\title{
A Study on Radiation Cooling Effect on Asphalt Concrete Pavement Using Basic Oxygen Furnace Slag to Replace Partial Aggregates
}

\author{
Yeou-Fong $\mathrm{Li}^{1}{ }^{1 *}$, Po-An Yang ${ }^{1}$, Chia-Ho $\mathrm{Wu}^{2}$, Ta-Wui Cheng ${ }^{2}(\mathbb{1})$ and Chih-Hong Huang ${ }^{3, *}$ \\ 1 Department of Civil Engineering, National Taipei University of Technology, 1, Sec. 3, Chung-Hsiao E. Rd., \\ Taipei 10608, Taiwan; 001068smhs@gmail.com \\ 2 Institute of Mineral Resources Engineering, National Taipei University of Technology, Taipei 10608, Taiwan; \\ cep03210@gmail.com (C.-H.W.); twcheng@ntut.edu.tw (T.-W.C.) \\ 3 Department of Architecture, National Taipei University of Technology, Taipei 10608, Taiwan \\ * Correspondence: yfli@mail.ntut.edu.tw (Y.-F.L.); huangch@mail.ntut.edu.tw (C.-H.H.)
}

Citation: Li, Y.-F.; Yang, P.-A.;

Wu, C.-H.; Cheng, T.-W.; Huang, C.-H.

A Study on Radiation Cooling Effect

on Asphalt Concrete Pavement Using Basic Oxygen Furnace Slag to Replace Partial Aggregates. Sustainability 2021, 13, 3708. https://doi.org/10.3390/ su13073708

Academic Editor: Jorge de Brito

Received: 22 February 2021

Accepted: 23 March 2021

Published: 26 March 2021

Publisher's Note: MDPI stays neutral with regard to jurisdictional claims in published maps and institutional affiliations.

Copyright: (C) 2021 by the authors. Licensee MDPI, Basel, Switzerland. This article is an open access article distributed under the terms and conditions of the Creative Commons Attribution (CC BY) license (https:/ / creativecommons.org/licenses/by/ $4.0 /)$.

\begin{abstract}
In this study, aggregates in asphalt concrete were partially replaced by basic oxygen furnace slag (BOFS) in proportions of $45 \mathrm{wt} . \%, 55 \mathrm{wt} . \%$, and $75 \mathrm{wt} . \%$. The thermal performances of the specimens are discussed based on the thermal conductivity, emissivity, and the indoor and outdoor temperature measurements. Consequently, $75 \mathrm{wt} \%$ of the specimen's aggregates were replaced by BOFS, which had a high emissivity of 0.86 across the sky window. In the indoor and outdoor tests, the temperature change was recorded to estimate the thermal performance of specimens. According to the quantitative calculation, when the substitution of BOFS was higher than $55 \mathrm{wt} . \%$, the specimens had a better radiation cooling ability. Among these specimens, the specimen with the BOFS substitution of $75 \mathrm{wt} . \%$ absorbed the most heat inside the body, contributing to less heat remaining in the environment. Furthermore, because Newton's cooling energy accounted for about $90 \%$ of the stored energy within $7 \mathrm{~h}$, the heat dissipation after the seventh hour was primarily radiation cooling, corresponding to the emission across the urban boundary layer. As for the mechanical properties, the stability value, indirect tensile strength, and British pendulum number (BPN) were in line with the specifications under the proper BOFS substitution. In conclusion, BOFS has great applicability in pavements due to its thermal performance and mechanical properties. It not only achieves the goal of urban heat island mitigation by radiation cooling, but also reflects the concept of resource sustainability.
\end{abstract}

Keywords: asphalt concrete; basic oxygen furnace slag; radiation cooling; emissivity; thermal conductivity

\section{Introduction}

In this century with booming industries, the enormous exploitation and consumption of energy results in the ever-increasing concentration of carbon dioxide worldwide, causing the greenhouse effect and extreme climate changes. According to the statistics from the National Oceanic and Atmospheric Administration (NOAA), the average temperature has increased by up to $0.18{ }^{\circ} \mathrm{C}$ per decade since 1981 . This has caused the snow in the polar regions to melt and subsequently raised the sea level [1]. Furthermore, the concentration of carbon dioxide started at about 265 ppm in 1850, reached 385 ppm in 2009, and even ascended to $407.4 \mathrm{ppm}$ in 2018. The vicious circle of greenhouse gas emission has a tremendous impact not only on metropolises but also environments. Under the circumstances, building envelopes and pavements with high heat capacities bring on and even worsen the urban heat island effect.

Nowadays, to mitigate the urban heat island effect, many studies have proposed to utilize reflective coating of asphalt concrete and have recorded its ambient temperatures 
and internal temperatures at different depths, exploring the principle of cooling with its spectral characteristics [2,3]. One study changed the color of asphalt concrete to discuss its reflection characteristics [4]; some even improved the reflectivity across specific wavelengths, mainly aimed at visible and near infrared light [5-7]; others made multi-layer structure coatings and compared their cooling benefits [8]. Furthermore, adding titanium dioxide with different weight ratios and particle sizes could improve the reflectivity of coating $[9,10]$. Hollow glass microspheres were substituted for fillers inside the asphalt concrete, optimizing the proportion for the best cooling effect with a simulated solar heating test [11]. This replacement could improve concrete's emissivity and also reduce thermal conductivity [12]. The lower thermal conductivity materials painted on the asphalt concrete were capable of preventing heat from passing through the coating [13]. The conductive multi-layer structures contributed to diverse applications, such as a radiation-cooling pavement in summer and heat preservation on permafrost $[14,15]$.

In terms of building envelopes, inorganic coating made from mineral powders has been painted on steel plates and concrete specimens. The temperatures and heat fluxes of the coated and uncoated surfaces and interiors were measured in the laboratory and in field tests and compared. The results showed that this coating had an obvious radiation cooling effect and great insulation ability owing to the emissivity and reflectivity. Furthermore, the adhesion and weather resistance were maintained at a certain level [16].

Apart from thermal properties, the mechanical properties of pavements need to be examined as well for practical use. Basic oxygen furnace slag (BOFS) is a byproduct of the steelmaking process. The converter is a by-product of the steelmaking process. A proper ratio for partially replacing aggregate with BOFS should be favorable for the development of bearing capacity and tensile strength when preparing asphalt or recycled concrete [17-21]. Furthermore, based on a two-year on-site test, it was found that the substitution of asphalt concrete entailed a longer life span with less damage in comparison with the original one [22]. Due to the roughness, multi-angularity, and rigidity of BOFS, the substitution concrete had better skid resistance, binding with bitumen, and also abrasion resistance [23]. Even when adopting the warm-mix or hot-mix asphalt approaches, this concrete still showed a great capability for resistance to deflection [24].

In this study, thermal and mechanical properties tests were done on the asphalt concrete specimens, in which aggregates were partially replaced by BOFS. Our previous research found that BOFS has a high far-infrared emissivity. After absorbing solar radiation, these specimens were capable of emitting the stored energy across the sky window $(8-13 \mu \mathrm{m})$ to the upper sky, reducing energy accumulation and retention in the atmosphere, thereby achieving the goal of urban heat island (UHI) mitigation. The surface skid resistance is needed for the development of a radiation-cooling pavement. Ceramic particles or fine sand particles were added to increase the pavement roughness and the British pendulum number (BPN). BOFS is a byproduct of steelmaking that can not only achieve the goal of radiation cooling but also meet the needs of resource sustainability.

\section{Materials and Their Properties}

BOFS, a byproduct of steel industries, has lower thermal conductivity compared to natural aggregates. Under the same heat source and with an identical time duration, BOFS has a slower temperature-raising rate. Due to the greater hardness, BOFS applied to asphalt concrete has a bearing capacity comparable to natural aggregates.

In this study, five specimens were designed and prepared, including one general asphalt concrete specimen, and the stone aggregates of the asphalt concrete specimens were replaced by BOFS at proportions of $45 \mathrm{wt} . \%, 55 \mathrm{wt} . \%, 65 \mathrm{wt} . \%$, and $75 \mathrm{wt} . \%$ respectively. The compositions of the aggregates used in the asphalt concrete specimens are shown in Table 1, and they are dense-graded and conform to ASTM D3515 [25]. The BOFS was also sieved with different sieve sizes. Then, we used BOFS aggregates to replace stone aggregates; the replacement percentage of every sieve size was the same. The content of 
asphalt to the aggregate mixture was $5.6 \mathrm{wt} . \%$, meeting the specification of between $2 \mathrm{wt} . \%$ to $10 \mathrm{wt} . \%$. The naming rules and descriptions of the specimens are shown in Table 2.

Table 1. Passing percentages of aggregates in dense-graded asphalt concrete specimens.

\begin{tabular}{ccccc}
\hline & & \multicolumn{3}{c}{ Passing Weight Percentage (\%) } \\
\cline { 3 - 5 } Sieve No. & Sieve Size (mm) & $\begin{array}{c}\text { ASTM } \\
\text { Specification }\end{array}$ & Specimens & $\begin{array}{c}\text { Permissible } \\
\text { Error }\end{array}$ \\
\hline $3 / 8$ & 9.5 & $90-100$ & 100 & $\pm 7 \%$ \\
No. 4 & 4.75 & $55-85$ & 76 & $\pm 6 \%$ \\
\hline No. 8 & 2.36 & $32-67$ & 46 & $\pm 5 \%$ \\
No. 16 & 1.18 & - & 31 & $\pm 4 \%$ \\
\hline No. 30 & 0.60 & - & 21 & $\pm 3 \%$ \\
\hline No. 50 & 0.30 & $7-23$ & 9 & 14 \\
\hline No. 100 & 0.15 & - & 5.6 & \\
\hline No. 200 & 0.075 & $2-10$ &
\end{tabular}

Table 2. Naming and description of the specimens.

\begin{tabular}{cc}
\hline Specimen & Description \\
\hline Benchmark & Standard asphalt concrete \\
BOF-45 & BOFS replacing 45 wt. $\%$ natural aggregates \\
BOF-55 & BOFS replacing 55 wt. $\%$ natural aggregates \\
BOF-65 & BOFS replacing 65 wt. $\%$ natural aggregates \\
BOF-75 & BOFS replacing 75 wt.\% natural aggregates \\
\hline
\end{tabular}

\subsection{Emissivity}

To identify the radiation cooling effect, the specimens $(10 \mathrm{~cm}$ in diameter and less than $2 \mathrm{~cm}$ in thickness) were placed in the customized apparatus and then heated to $35^{\circ} \mathrm{C}$ and $80^{\circ} \mathrm{C}$, respectively. To reflect the reality of usage, it was necessary to confirm that no aggregate was exposed on the measured surface. The environmental causes were reduced as much as possible in the measurements. When the specimens were heated, the infrared light emitted from the specimens was measured by Fourier transform infrared spectrometer (FT-IR) (Invenior, Bruker, Karlsruhe, Germany) in the range of 4000-600 $\mathrm{cm}^{-1}(3-16.67 \mu \mathrm{m})$. The raw data were the result of optical interference.

Through the Fourier transform, the emissivity of heated specimens was calculated compared to the standard blackbody. The emissivity of five specimens was classified into 3-16.7 $\mu \mathrm{m}$ and $8-13 \mu \mathrm{m}$, as shown in Figure $1 \mathrm{a}, \mathrm{b}$, respectively. The corresponding average emissivity for $3-16.67 \mu \mathrm{m}$ and $8-13 \mu \mathrm{m}$ is presented in Table 3 . When the substitution of BOFS exceeded $65 \mathrm{wt} . \%$, the emissivity was higher than the benchmark specimen. Among these, the BOF-75 specimen possessed the highest emissivity of 0.88 for 3-16.67 $\mu \mathrm{m}$ and 0.86 for $8-13 \mu \mathrm{m}$.

Table 3. Average emissivity of benchmark and BOFS specimens for 3-16.67 $\mu \mathrm{m}$ and 8-13 $\mu \mathrm{m}$.

\begin{tabular}{cccccc}
\hline Wavelength $(\boldsymbol{\mu m})$ & Benchmark & BOF-45 & BOF-55 & BOF-65 & BOF-75 \\
\hline $3-16.67$ & 0.844 & 0.792 & 0.822 & 0.872 & 0.877 \\
$8-13$ & 0.829 & 0.797 & 0.805 & 0.870 & 0.855 \\
\hline
\end{tabular}




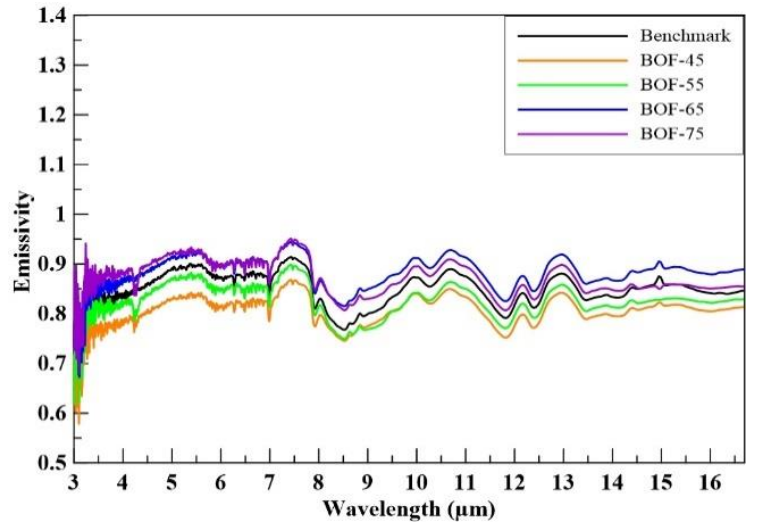

(a)

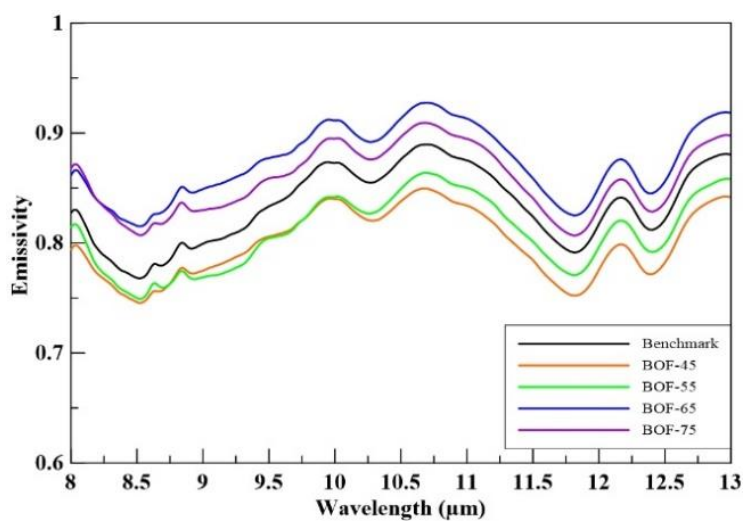

(b)

Figure 1. Emissivity of benchmark and basic oxygen furnace slag (BOFS) specimens for (a) 3-16.67 $\mu \mathrm{m}$ and (b) 8-13 $\mu \mathrm{m}$.

\subsection{Thermal Conductivity}

Thermal conductivity is one of the important parameters of thermal performance for materials. The conductivity was tested with a quick thermal conductivity meter (QTM500, KEM, Tokyo, Japan) used on the specimens. After calibration, the slope equaling the temperature divided by the logarithmic time represents the thermal conductivity coefficient. The larger the slope, the faster the materials conduct heat, and vice versa. In this study, the thermal conductivity of each specimen was averaged.

As illustrated in Figure 2, the thermal conductivity showed a downward trend with the increasing replacement amount of BOFS. Among the specimens, the BOF-75 specimen had the lowest conductivity of $1.17 \mathrm{~W} / \mathrm{m}-\mathrm{K}$, which means it had better heat-insulating properties than the others. As a consequence, BOFS was taken as a good heat-insulating material.

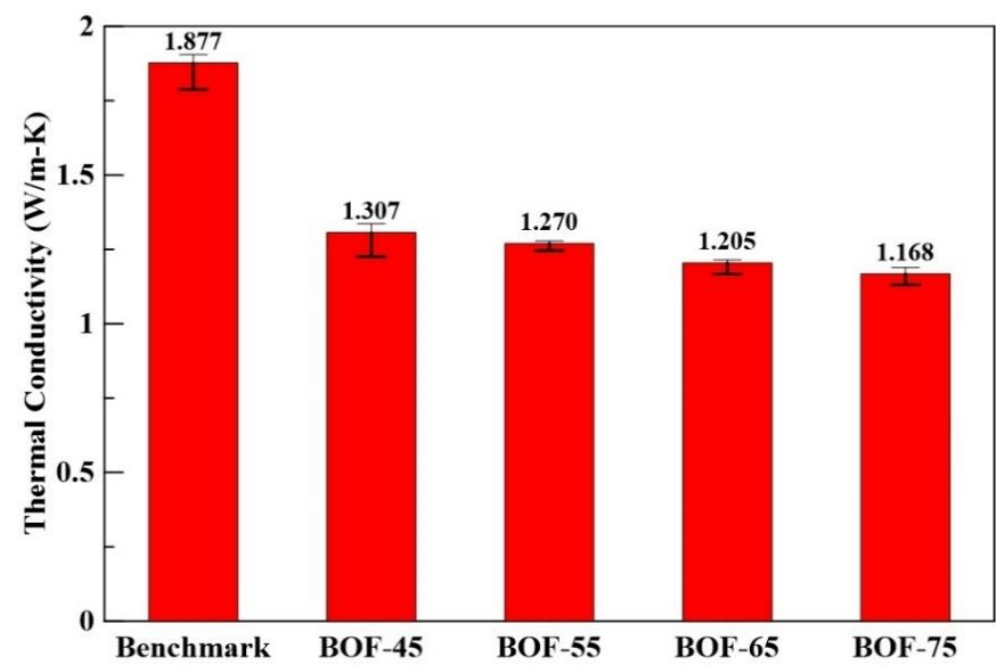

Figure 2. Thermal conductivities of BOFS and benchmark specimens.

\section{Experimental Measurement Methods}

In this study, the experimental measurement was divided into two aspects: thermal performance and mechanical performance. The thermal performance was measured in the laboratory and also outdoors; the mechanical performance, including the stability value, indirect tensile strength, and British pendulum number, reflects the feasibility of practical application in engineering. 


\subsection{Indoor Temperature Measurement}

To find the best radiation cooling among the benchmark and BOFS specimens, this experimental measurement was conducted in the laboratory and outdoors. The fabrication of the specimen started with a stir-fry pan and was evenly mixed, and the asphalt concrete was poured into the customized steel mold and then compacted to form a specimen. To simulate the actual pavement, the size of the specimen was molded as $50 \times 50 \mathrm{~cm}$ and with a thickness of $5 \mathrm{~cm}$. Meanwhile, the aggregate layer was $13 \mathrm{~cm}$ in thickness underneath the asphalt concrete.

To simulate a sunlight environment in the laboratory, halogen lamps and infrared lamps were used as the heat source in this apparatus to irradiate visible light and infrared light, which provide the majority of solar radiation. The ratios of visible light and infrared light remained at $44 \%$ and $53 \%$. Two different radiation intensities, $623 \mathrm{~W} / \mathrm{m}^{2}$ and $436 \mathrm{~W} / \mathrm{m}^{2}$, were tested. According to the previous results of outdoor measurements in summer at Taipei City, the radiation intensity of the heat source should be adjusted to $623 \mathrm{~W} / \mathrm{m}^{2}$, composed of $279 \mathrm{~W} / \mathrm{m}^{2}$ from the halogen lamps erected at $30 \mathrm{~cm}$ above the specimen and $344 \mathrm{~W} / \mathrm{m}^{2}$ from the infrared lamp erected at $33 \mathrm{~cm}$ above the specimen. To simulate the surface temperature of pavement in winter at Taipei City, the radiation intensity was adjusted to $436 \mathrm{~W} / \mathrm{m}^{2}$ with the maximum surface temperature of $65^{\circ} \mathrm{C}$. Schematic diagrams of the apparatus used in the indoor temperature measurement under the radiation intensities of (a) $623 \mathrm{~W} / \mathrm{m}^{2}$ and (b) $436 \mathrm{~W} / \mathrm{m}^{2}$ are shown in Figure 3.

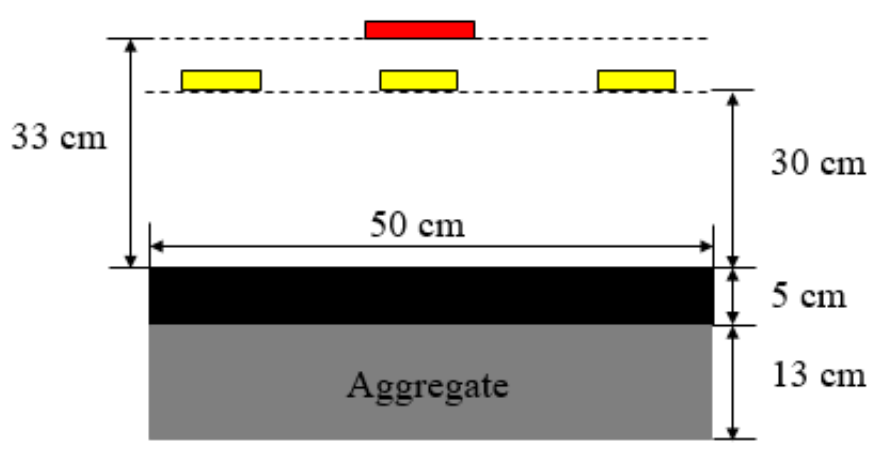

Asphalt Concrete

Infrared light

(a)

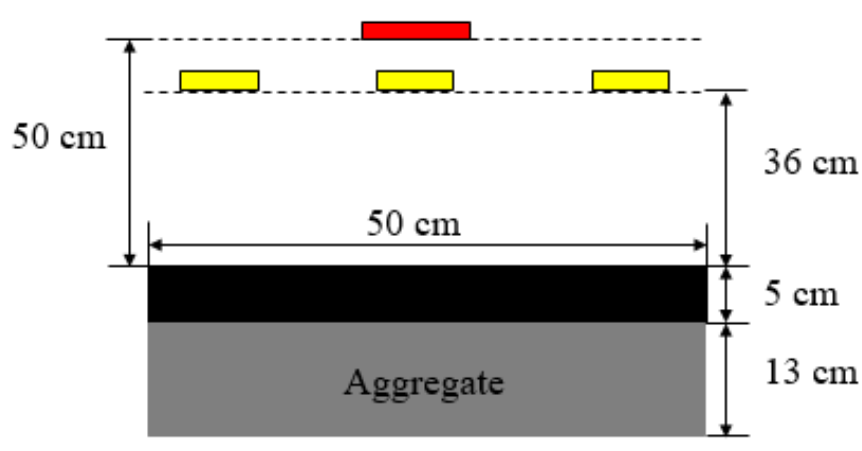

Asphalt Concrete

Infrared light

(b)

Figure 3. Schematic diagrams of the apparatus used in the indoor temperature measurement under the radiation intensities of (a) $623 \mathrm{~W} / \mathrm{m}^{2}$ and (b) $436 \mathrm{~W} / \mathrm{m}^{2}$.

The test was conducted in a shaded and airtight room; the specimen was surrounded by Styrofoam. To avoid errors from environmental factors, such as light and ambient temperature, strict conditions were necessary. The thermal cables, which were attached on the surface or buried inside the asphalt concrete, recorded the temperature change at different depths. The experimental apparatus and a schematic diagram of the sensor installation are shown in Figure 4a,b, respectively.

\subsection{Outdoor Temperature Measurement}

In order to measure their thermal performance, asphalt concrete specimens were exposed to solar radiation, and the outdoor test was conducted on the empty top floor, without shelter, in the summer in 2020 on the roof of the Department of Civil Engineering building, National Taipei University of Technology, Taipei City. The size of the specimens, $50 \times 50 \times 5 \mathrm{~cm}$, was the same as for those used in the indoor test. Likewise, the aggregate layer was laid $13 \mathrm{~cm}$ in thickness beneath the specimens to simulate a real pavement. Also, 
thermal cables were installed to measure the temperature change, as shown in Figure $4 \mathrm{~b}$. The outdoor temperature measurement setup is shown in Figure 5.

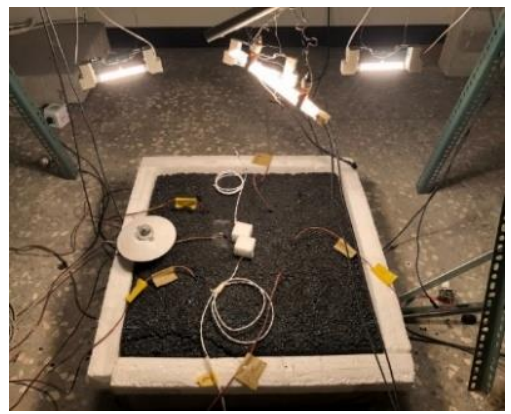

(a)

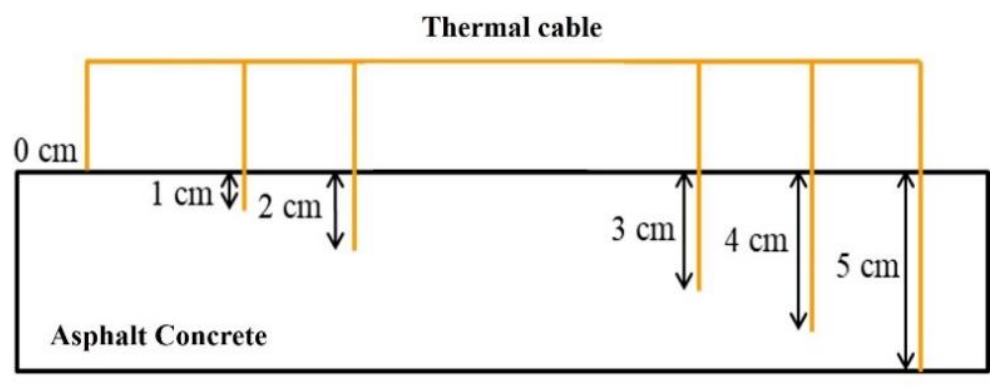

(b)

Figure 4. (a) Experimental apparatus, (b) schematic diagram of sensor installation.

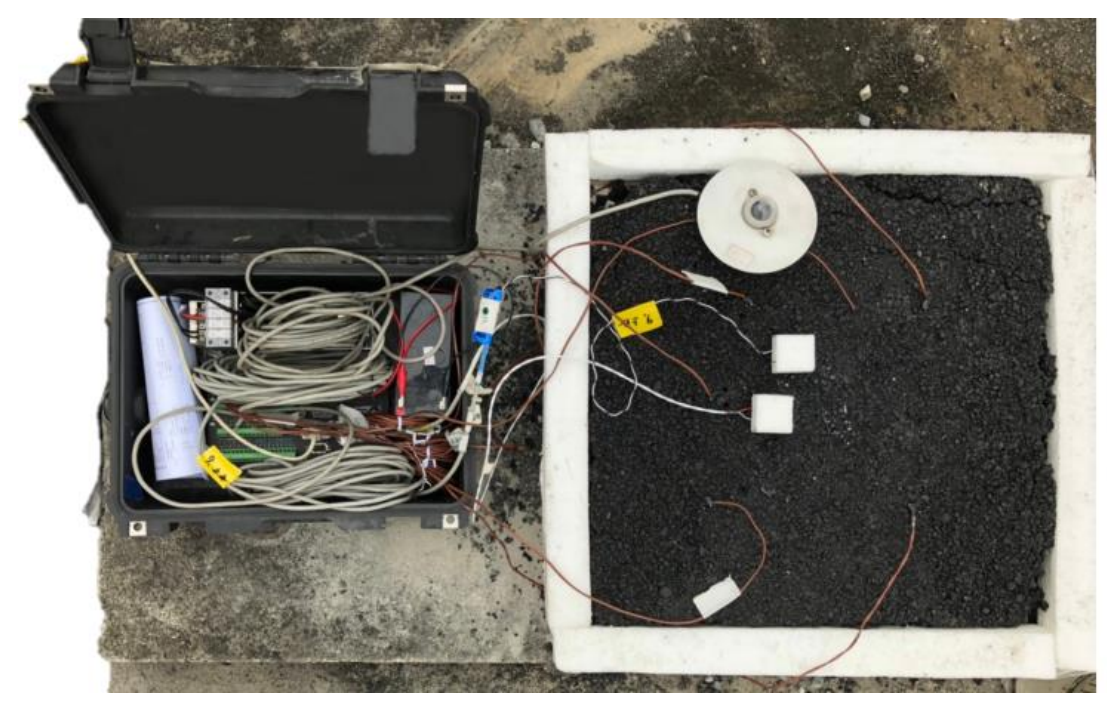

Figure 5. The outdoor temperature measurement equipment and setup.

\subsection{Mechanical Properties}

The asphalt concrete specimen without BOFS, named the benchmark specimen, and the asphalt concrete with BOFS in the three ratios were prepared with a Marshall apparatus according to the ASTM D6926 standard [26,27]. First, following the mixing formula and substitution ratio, the asphalt and aggregates were mixed by stirring until uniform. The mixture was quickly poured into the steel mold. Then, through 75 times compaction on both sides and then cooling down for about one day, the asphalt concrete specimen was demolded. Its average diameter and height were measured with an electronic Vernier caliper, with an accuracy of $0.01 \mathrm{~mm}$.

The stability value, indirect tensile strength, and British pendulum number are discussed below. Following AI SS-1 set by the Asphalt Institute, the stability values of specimens were measured and specimens were sunk into a constant $60{ }^{\circ} \mathrm{C}$ water tank for $30 \mathrm{~min}$ and tested with the computer-controlled automatic Marshall apparatus (Ye-Chance Enterprise Co., Taipei, Taiwan) at a uniform rate of $50.8 \mathrm{~mm} / \mathrm{min}$. As the pavement is subjected to severe traffic loadings, the stability value must be higher than $8.006 \mathrm{kN}$ to comply with the standard.

The indirect tensile strength was measured according to ASTM D6931 [28]. The specimen was attached between two load stripes and was loaded radially at a speed of $50 \pm 5 \mathrm{~mm} / \mathrm{min}$. The width of stripes was $12.7 \pm 0.3 \mathrm{~mm}$, complying with the standard. 
The specimen was exposed to $25{ }^{\circ} \mathrm{C}$ water for 30-120 min, and the maximum load at fracture was measured. The indirect tensile strength can be calculated from Equation (1), as follows.

$$
S t=\frac{2000 \times P}{\pi \times t \times D}
$$

In Equation (1), $S_{t}$ is the indirect tensile strength $(\mathrm{kPa}), P$ is the maximum load $(\mathrm{N})$, $t$ is the average thickness of the specimen before test $(\mathrm{mm})$, and $D$ is the average diameter of the specimen before testing ( $\mathrm{mm}$ ). Conforming to ASTM E303, the British pendulum number was measured on the surface of the $50 \times 50 \times 5 \mathrm{~cm}$ specimen with a calibrated British pendulum anti-sliding tester (EL42-6000, ELE International, Leighton Buzzard, $\mathrm{UK})$. In the end, the averaged value was regarded as the BPN value, which represents the anti-skid ability.

\section{Results and Discussions}

\subsection{Indoor Temperature Measurement under Radiation Intensity of $623 \mathrm{~W} / \mathrm{m}^{2}$}

The indoor temperature measurement of the specimens was divided into a heating period under a radiation intensity of $623 \mathrm{~W} / \mathrm{m}^{2}$ and cooling period without radiation intensity. The temperature-time relationships and temperature profiles of specimens were drawn and discussed.

\subsubsection{Heating Period}

The specimens were heated constantly for $24 \mathrm{~h}$ under the radiation intensity of $623 \mathrm{~W} / \mathrm{m}^{2}$. Figure 6 shows the temperature-time relationships in the heating period under the radiation intensity of $623 \mathrm{~W} / \mathrm{m}^{2}$. As seen from Figure 6 , the specimens reached thermal equilibrium at $24 \mathrm{~h}$. In Figure $6 \mathrm{a}$, the highest temperature of $85{ }^{\circ} \mathrm{C}$ occurred in BOF-75 at the end of 24 heating hours and the temperature decreased in the order of BOF-55 and then BOF-45, while the benchmark was $70^{\circ} \mathrm{C}$. No obvious order was observed at the depths of $1 \mathrm{~cm}$ and $2 \mathrm{~cm}$, as shown in Figure 6b,c. As seen in Figure 6d, BOF-75 possessed the lowest temperature at the depth of $3 \mathrm{~cm}$.

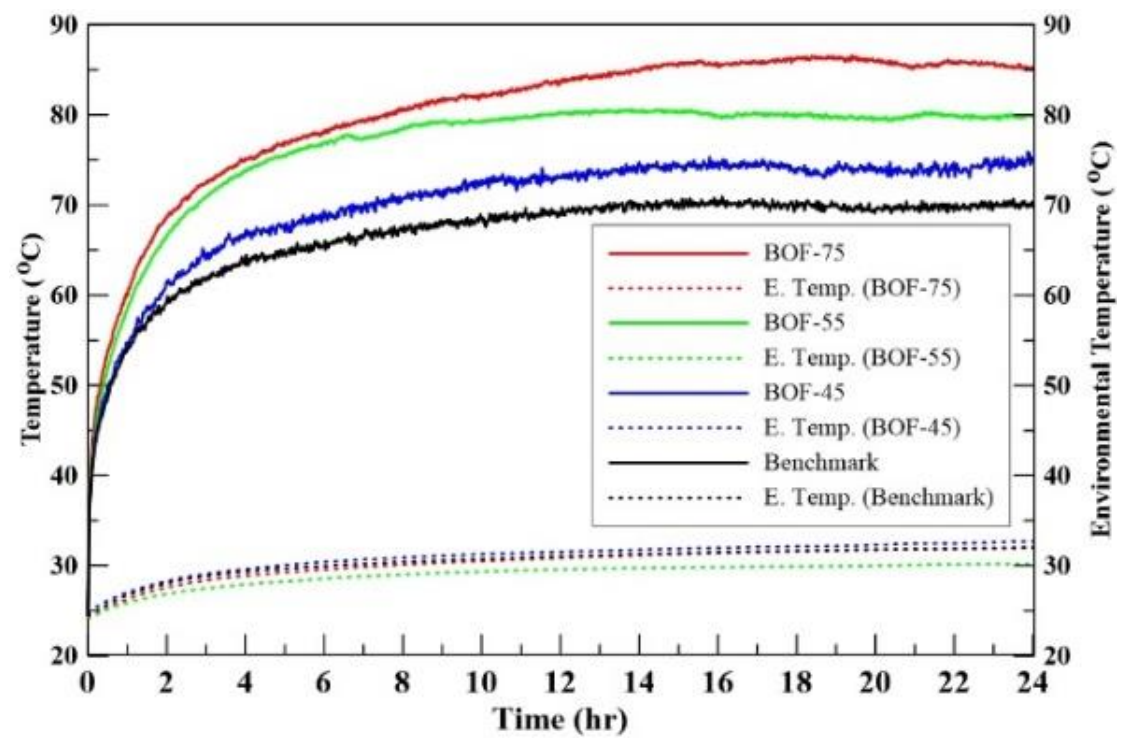

(a)

Figure 6. Cont. 


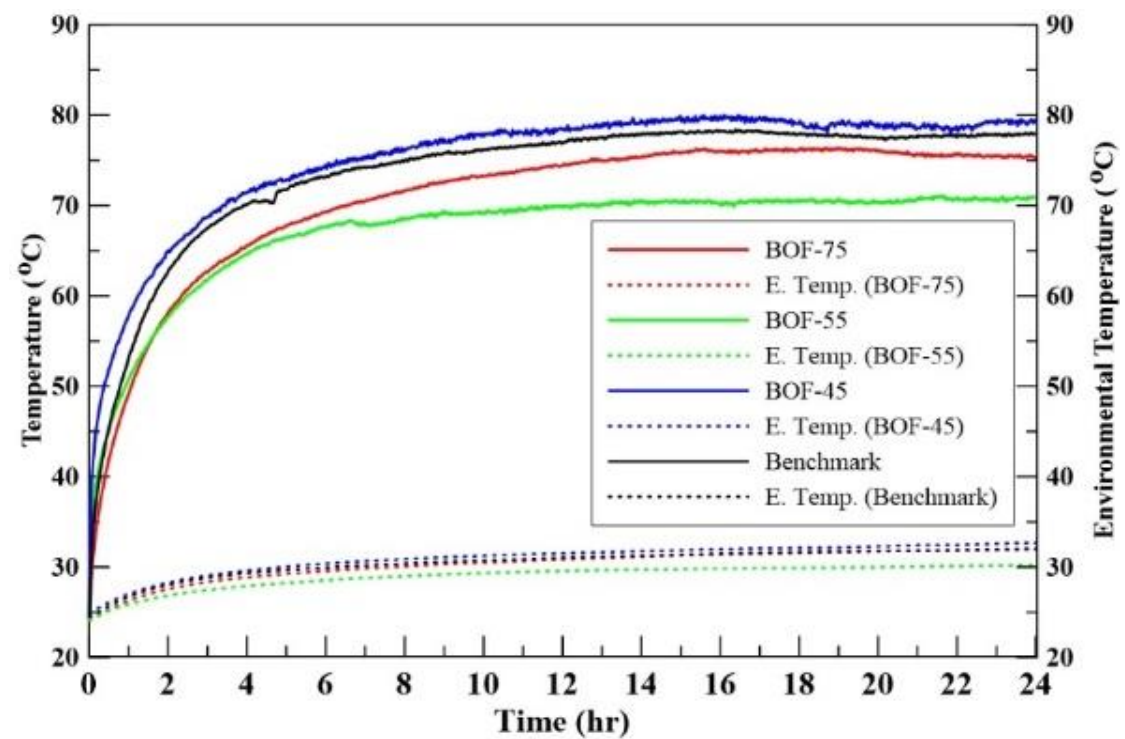

(b)

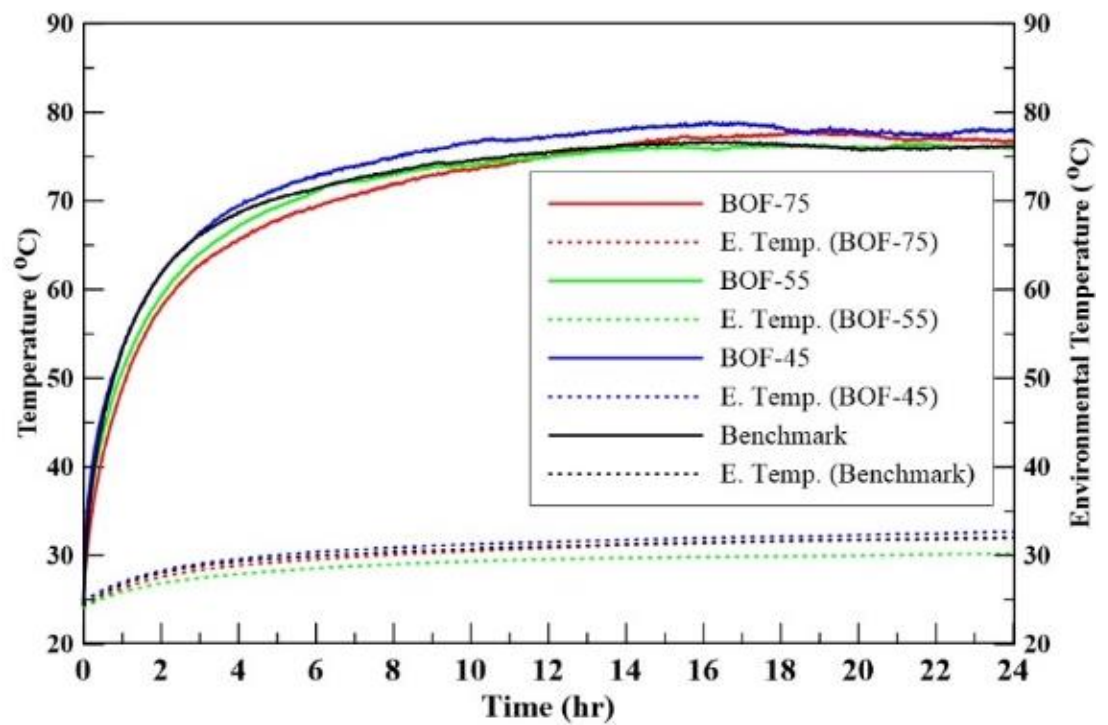

(c)

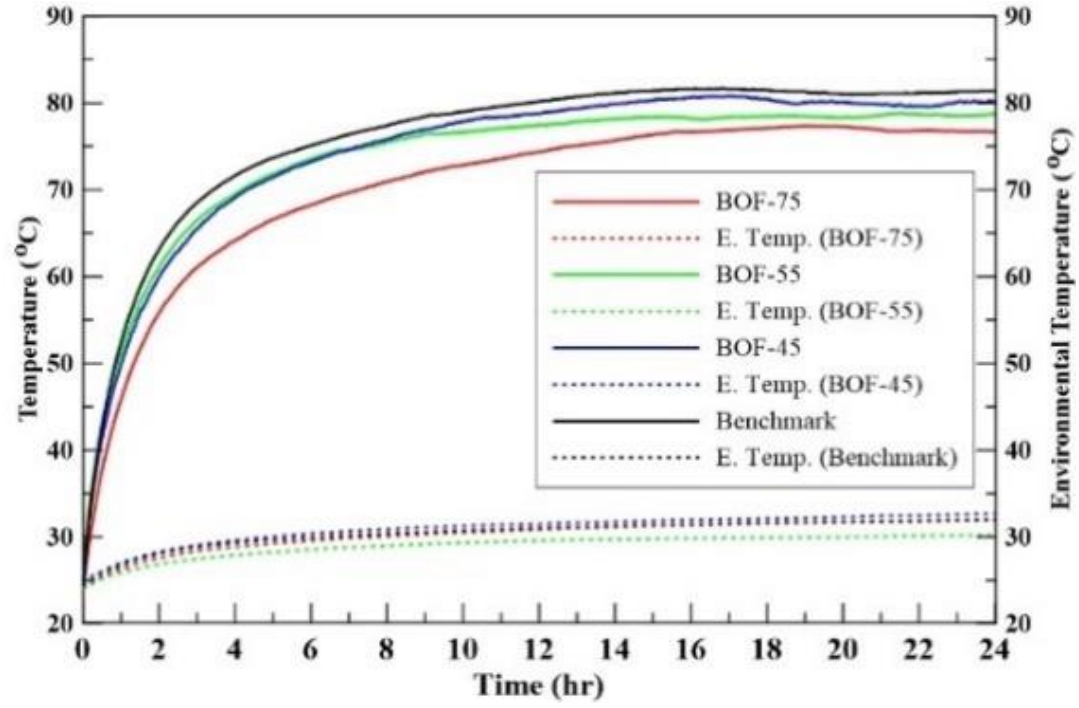

(d)

Figure 6. Cont. 


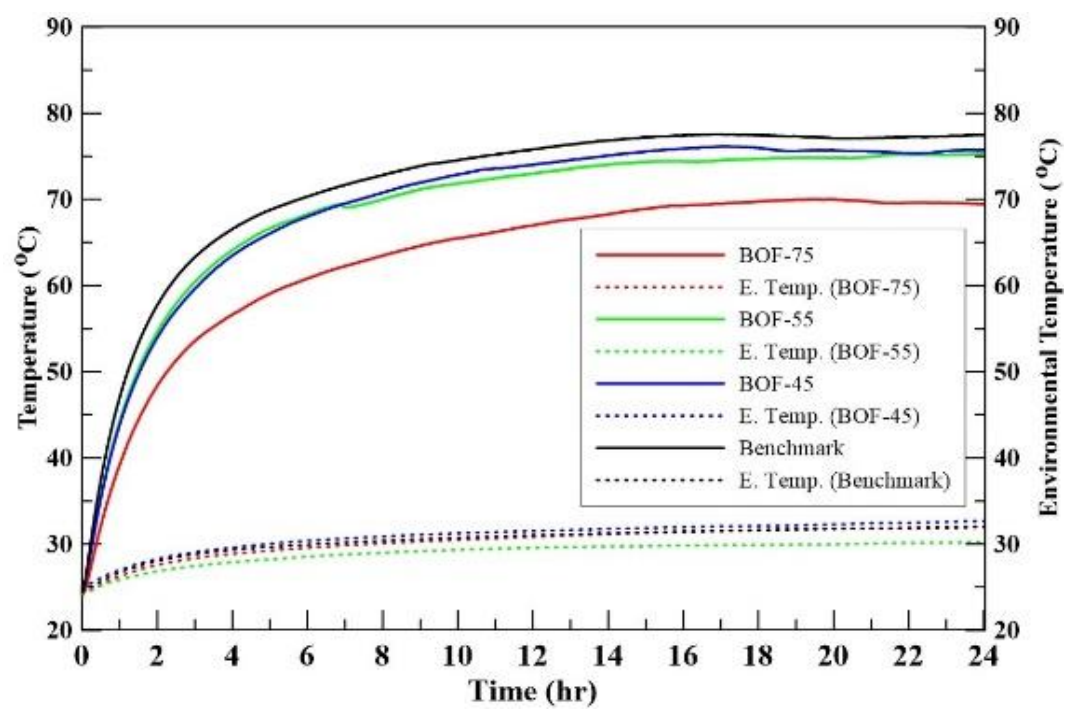

(e)

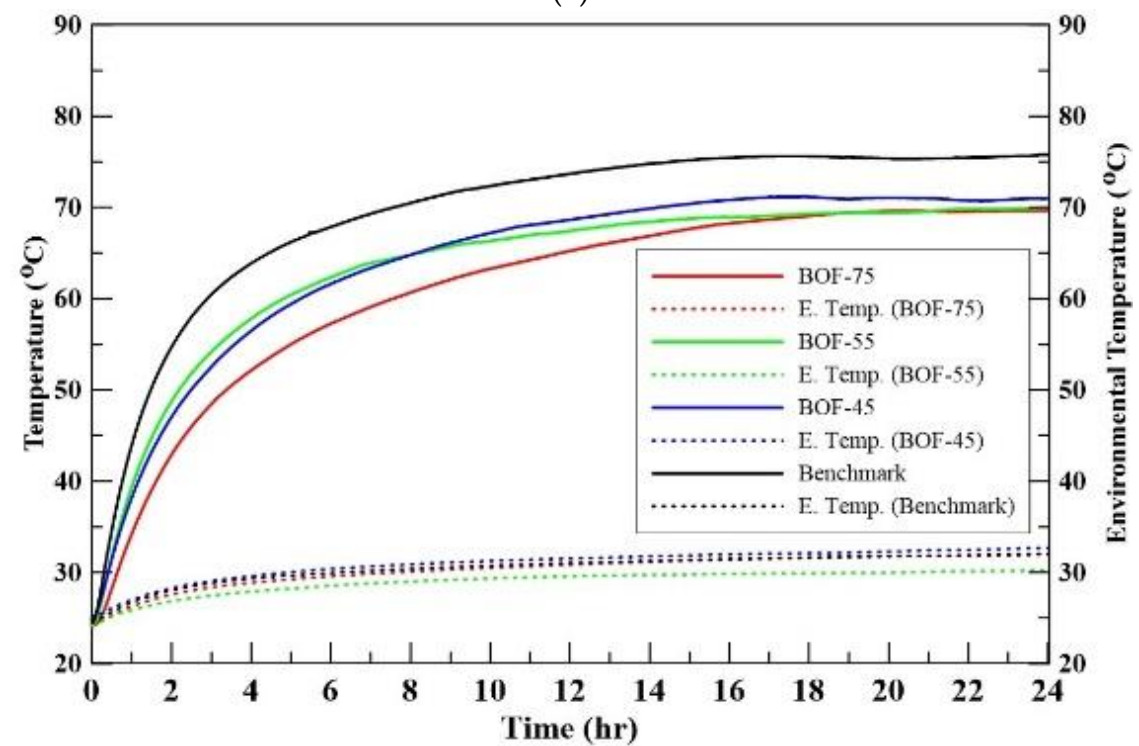

(f)

Figure 6. Temperature-time relationships in the heating period under the radiation intensity of $623 \mathrm{~W} / \mathrm{m}^{2}$ at (a) the top surface; (b) $1 \mathrm{~cm}$ depth; (c) $2 \mathrm{~cm}$ depth; (d) $3 \mathrm{~cm}$ depth; (e) $4 \mathrm{~cm}$ depth; and (f) $5 \mathrm{~cm}$ depth.

There were two heat sources: one was the halogen and infrared lamps, and the other was the accumulated heat underneath the asphalt concrete; both substantially affected the temperature at the depths of $1 \mathrm{~cm}$ and $2 \mathrm{~cm}$.

The order of the temperature on the surface was totally in reverse compared to the temperature at the depths of $3 \mathrm{~cm}$ and deeper. The temperatures in profile taken from the thermal equilibrium condition at the end of 24 heating hours are shown in Table 4 and Figure 7. The depth-temperature curves of BOF-55 and BOF-75 were similar. In the profile, their temperatures on the surface were higher than inside and broadly decreased when going deeper. On the other hand, the depth-temperature curve of the benchmark and BOF-45 were similar in another way: the highest temperature was recorded at the depth of $3 \mathrm{~cm}$. Compared to the benchmark specimen, although all the specimens with BOFS replacements had hotter surfaces, their temperatures were lower starting at $3 \mathrm{~cm}$ depths, especially BOF-75. 
Table 4. Temperature $\left({ }^{\circ} \mathrm{C}\right)$ corresponding to different depths at the end of 24 heating hours under the radiation intensity of $623 \mathrm{~W} / \mathrm{m}^{2}$.

\begin{tabular}{|c|c|c|c|c|c|}
\hline Depth & Specimen & Benchmark & BOF-45 & BOF-55 & BOF-75 \\
\hline & $0 \mathrm{~cm}$ & 69.86 & 75.14 & 79.88 & 85.10 \\
\hline & $1 \mathrm{~cm}$ & 77.94 & 79.56 & 70.83 & 75.33 \\
\hline & $2 \mathrm{~cm}$ & 76.16 & 78.06 & 75.94 & 76.72 \\
\hline & $3 \mathrm{~cm}$ & 81.40 & 80.20 & 78.71 & 76.63 \\
\hline & $4 \mathrm{~cm}$ & 77.49 & 75.75 & 75.29 & 69.42 \\
\hline & $5 \mathrm{~cm}$ & 75.77 & 70.98 & 69.97 & 69.64 \\
\hline
\end{tabular}

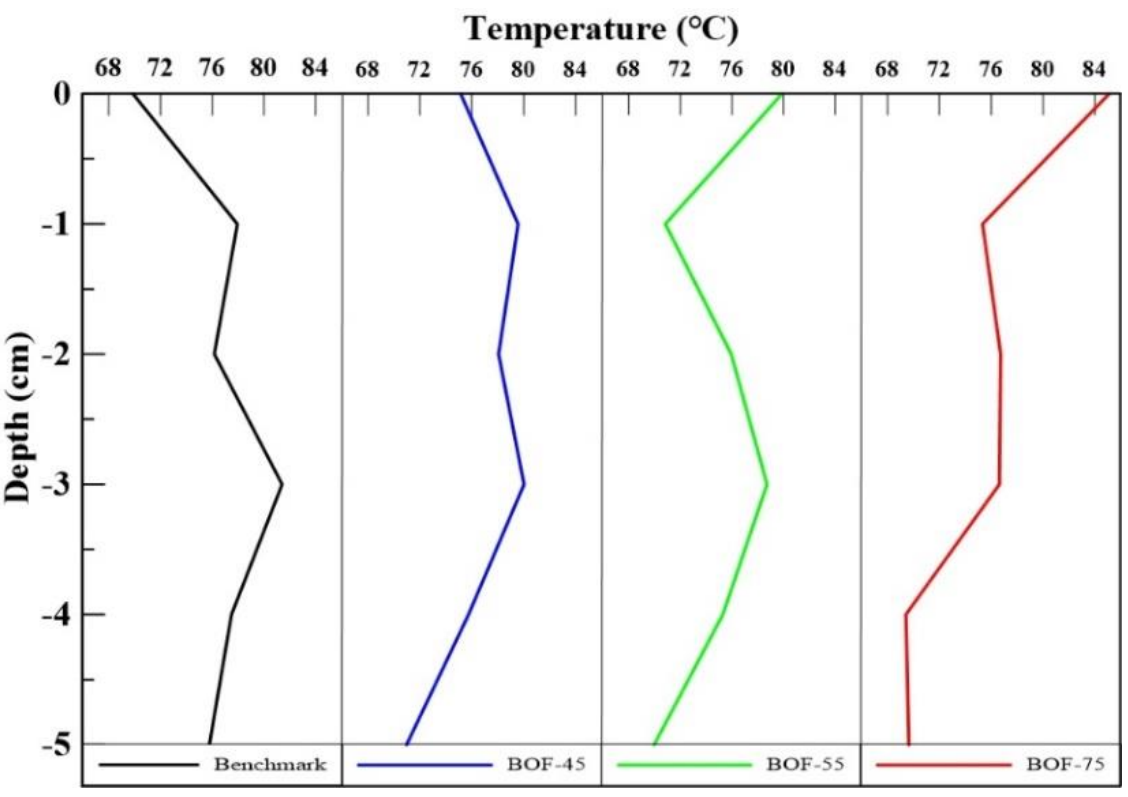

Figure 7. Depth-temperature profile of specimens at the end of 24 heating hours under the radiation intensity of $623 \mathrm{~W} / \mathrm{m}^{2}$.

\subsubsection{Cooling Period}

All the lamps were turned off after $24 \mathrm{~h}$ of heating; the temperature change in the subsequent 1-h cooling was recorded and shown in Figure 8. When the heat source was removed, the heat obviously dissipated from the specimen. The cooling rate at each depth gradually became similar, and the temperature-time relationships of all specimens at the depth of $3 \mathrm{~cm}$ were the most concentrated.

The depth-temperature profiles of specimens within five cooling hours in the cooling period are shown in Figure 9. In the beginning of the cooling period, the sequences of the surface temperatures are the same. Notably, all the specimens containing BOFS possessed a higher temperature at a depth of $5 \mathrm{~cm}$ than $3 \mathrm{~cm}$. As seen from Figure 9, the temperature of the benchmark specimen at the depth of $3 \mathrm{~cm}$ was higher than the temperature at $5 \mathrm{~cm}$ in the first hour, but the temperature at a depth of $3 \mathrm{~cm}$ was less than the temperature at a depth of $5 \mathrm{~cm}$ at other times.

\subsection{Indoor Temperature Measurement under Radiation Intensity of $436 \mathrm{~W} / \mathrm{m}^{2}$}

The indoor temperature measurement of the specimens was divided into a heating period under a radiation intensity of $436 \mathrm{~W} / \mathrm{m}^{2}$ and a cooling period without radiation intensity. The temperature-time relationships and temperature profiles of specimens were determined and discussed. 


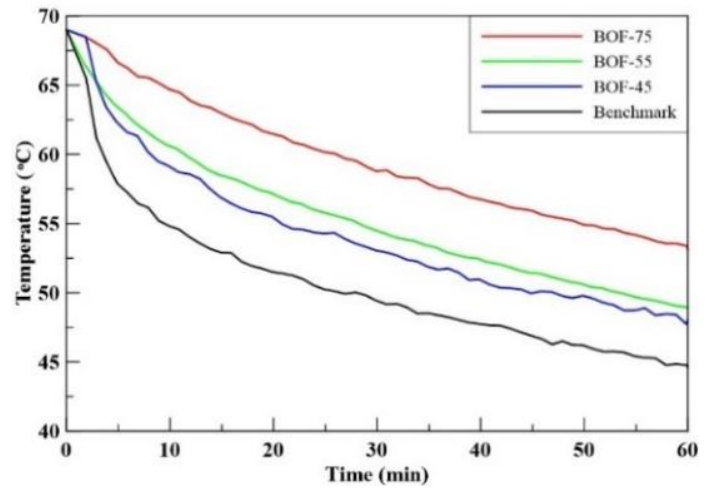

(a)

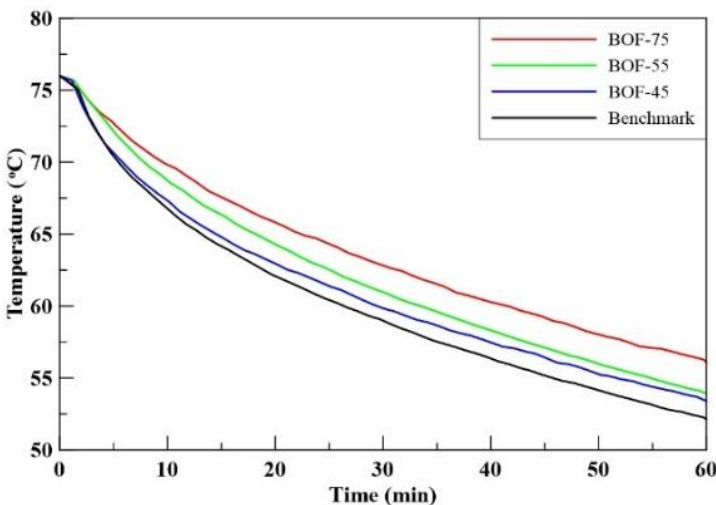

(c)

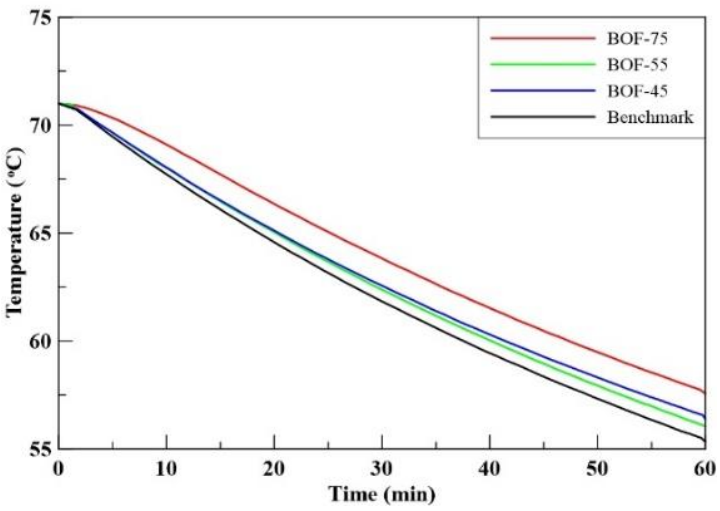

(e)

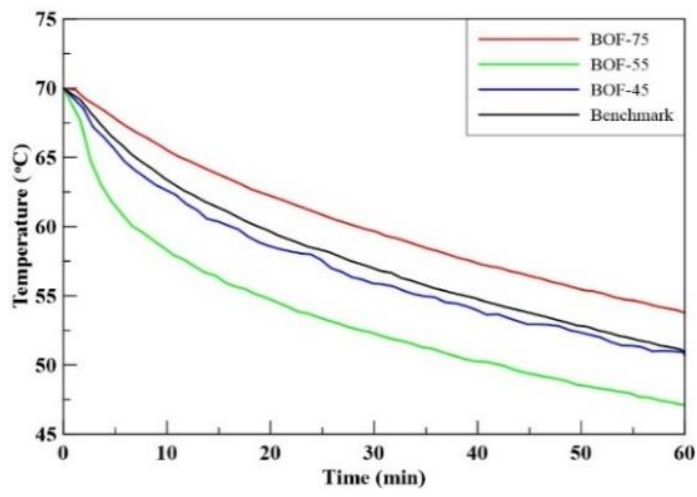

(b)

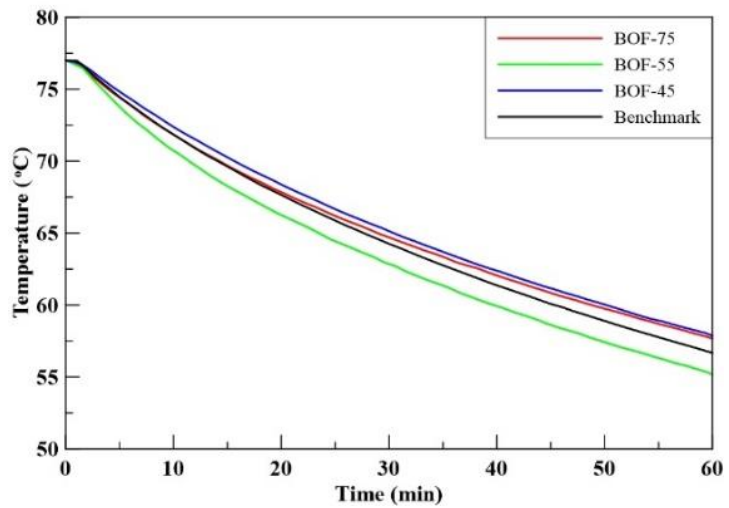

(d)

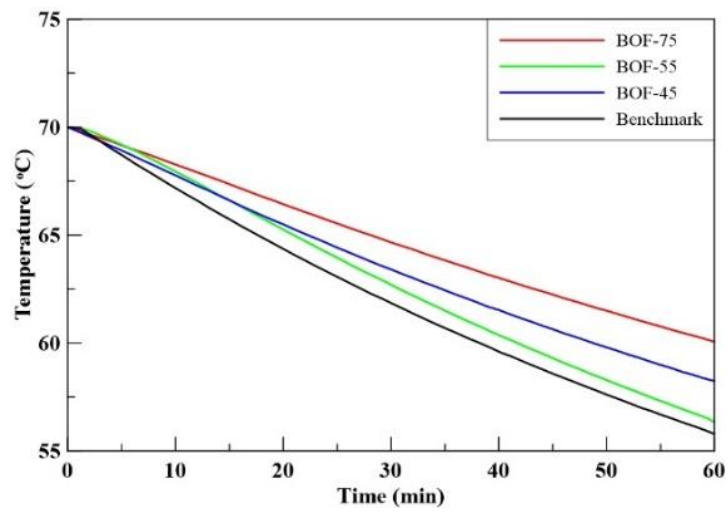

(f)

Figure 8. Temperature-time relationships in the cooling period at (a) the top surface; (b) $1 \mathrm{~cm} \mathrm{depth;} \mathrm{(c)} 2 \mathrm{~cm}$ depth; (d) $3 \mathrm{~cm}$ depth; (e) $4 \mathrm{~cm}$ depth; and (f) $5 \mathrm{~cm}$ depth.

\subsubsection{Heating Period}

The specimens were heated constantly for $24 \mathrm{~h}$ under the radiation intensity of $436 \mathrm{~W} / \mathrm{m}^{2}$ until the temperatures of the specimens reached a stable state. As shown in Figure 10a, BOF-75 had the highest temperature of $66.82^{\circ} \mathrm{C}$ and BOF-55 had the next highest temperature of $64.74{ }^{\circ} \mathrm{C}$, corresponding with the results under the radiation intensity of $623 \mathrm{~W} / \mathrm{m}^{2}$. Although the order between BOF-45 and the benchmark was disrupted and did not correspond with the previous results, the temperature difference between $56.95{ }^{\circ} \mathrm{C}$ and $57.69^{\circ} \mathrm{C}$ was not significant. As shown in Figure $10 \mathrm{~b}, \mathrm{c}$, the temperature changes at the depths of $1 \mathrm{~cm}$ and $2 \mathrm{~cm}$ were similar to the results under the radiation intensity of $623 \mathrm{~W} / \mathrm{m}^{2}$. Influenced by the upper and lower heat sources, it was difficult to find the order at these two depths. As shown in Figure 10d, the temperatures at the depth of $3 \mathrm{~cm}$ were in descending order of BOF-75 $\left(63.46^{\circ} \mathrm{C}\right)$, BOF-55 $\left(63.53^{\circ} \mathrm{C}\right)$, BOF-45 
$\left(64.17^{\circ} \mathrm{C}\right)$, and then the benchmark $\left(65.65^{\circ} \mathrm{C}\right)$. This order happened for the results under the radiation intensity of $623 \mathrm{~W} / \mathrm{m}^{2}$, which was in reverse on the surface. As shown in Figure 10e,f, the temperature-time relationship at the depths of $4 \mathrm{~cm}$ and $5 \mathrm{~cm}$ were similar to those in Figure 10d.

Temperature $\left({ }^{\circ} \mathrm{C}\right)$

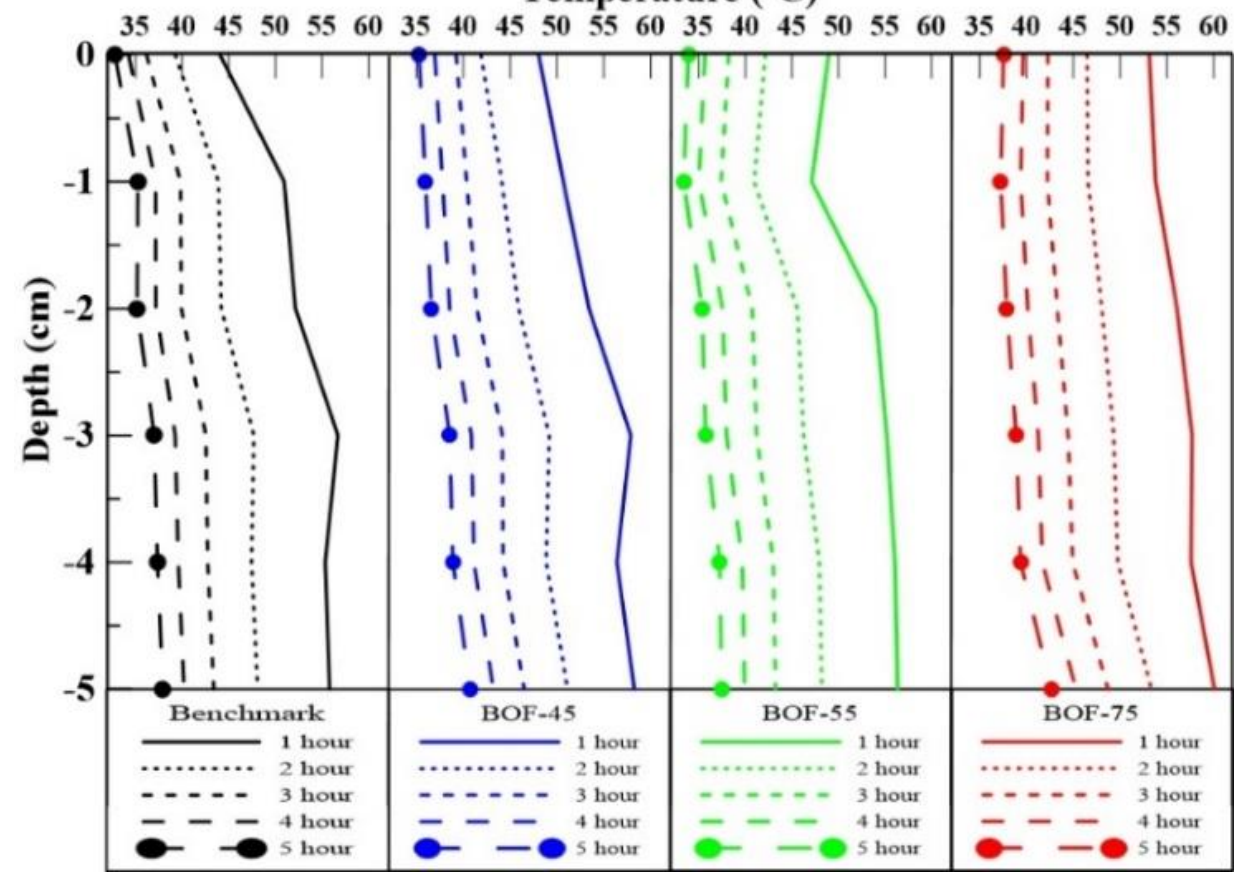

Figure 9. Depth-temperature profile of specimens within five cooling hours in the cooling period.

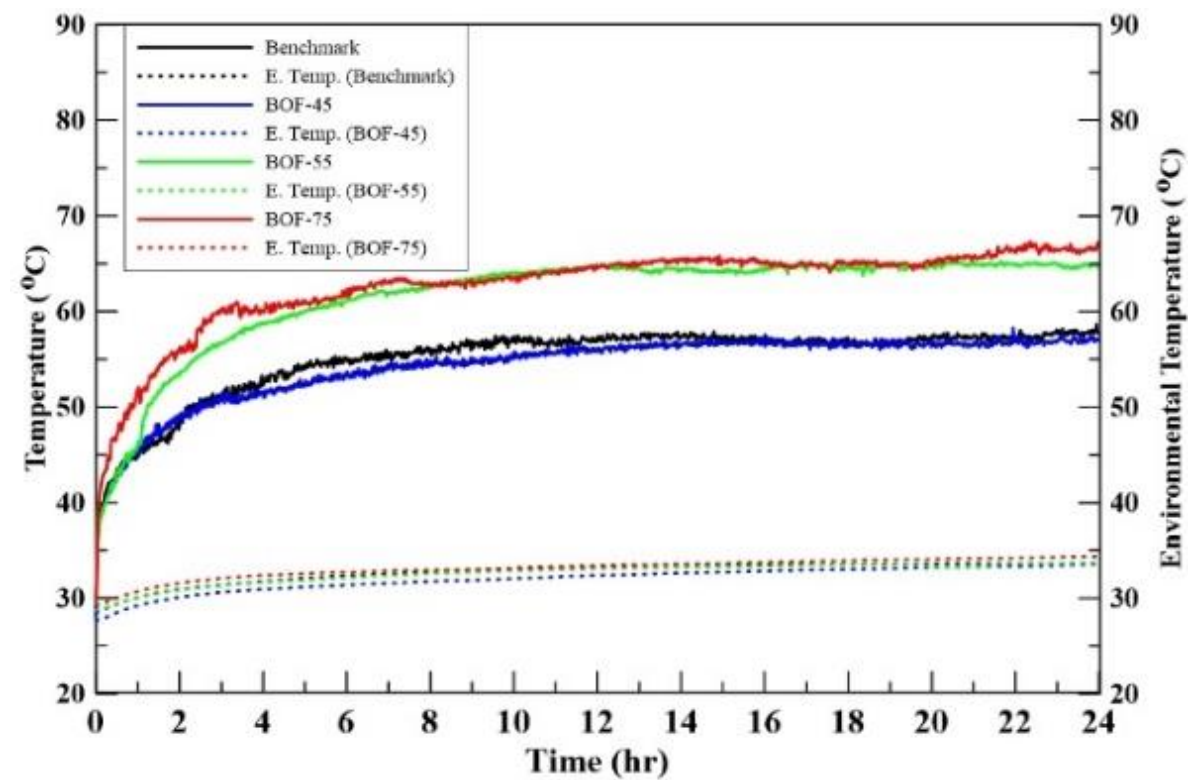

(a)

Figure 10. Cont. 


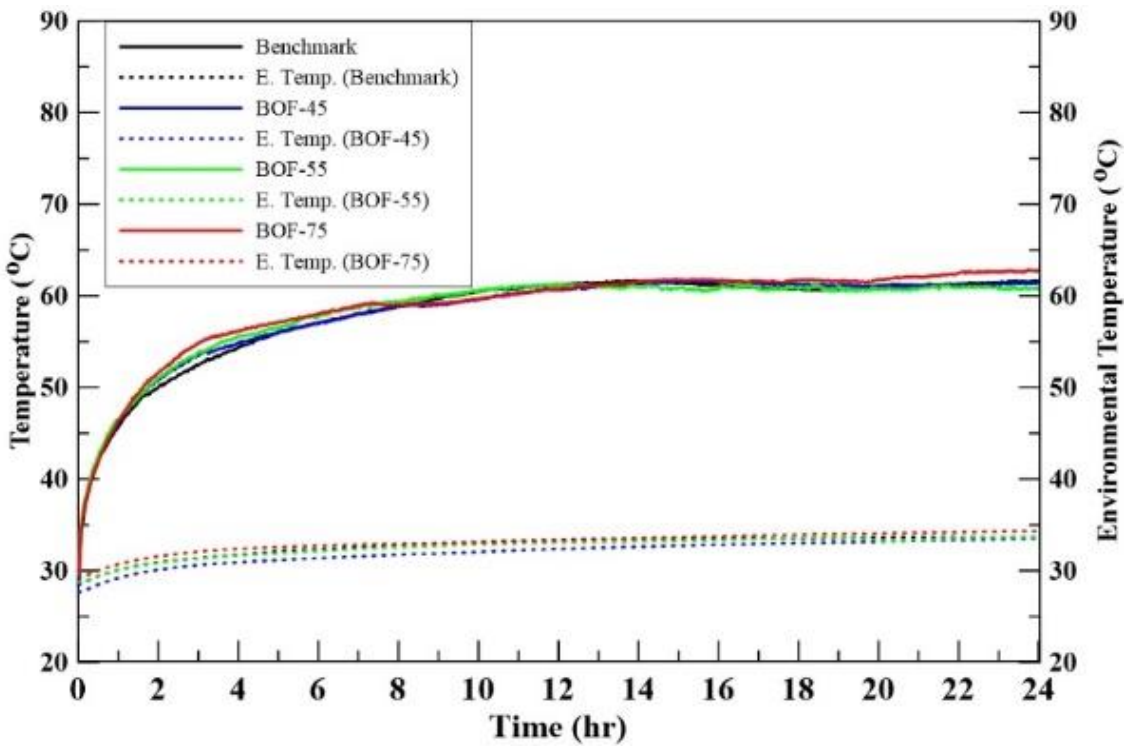

(b)

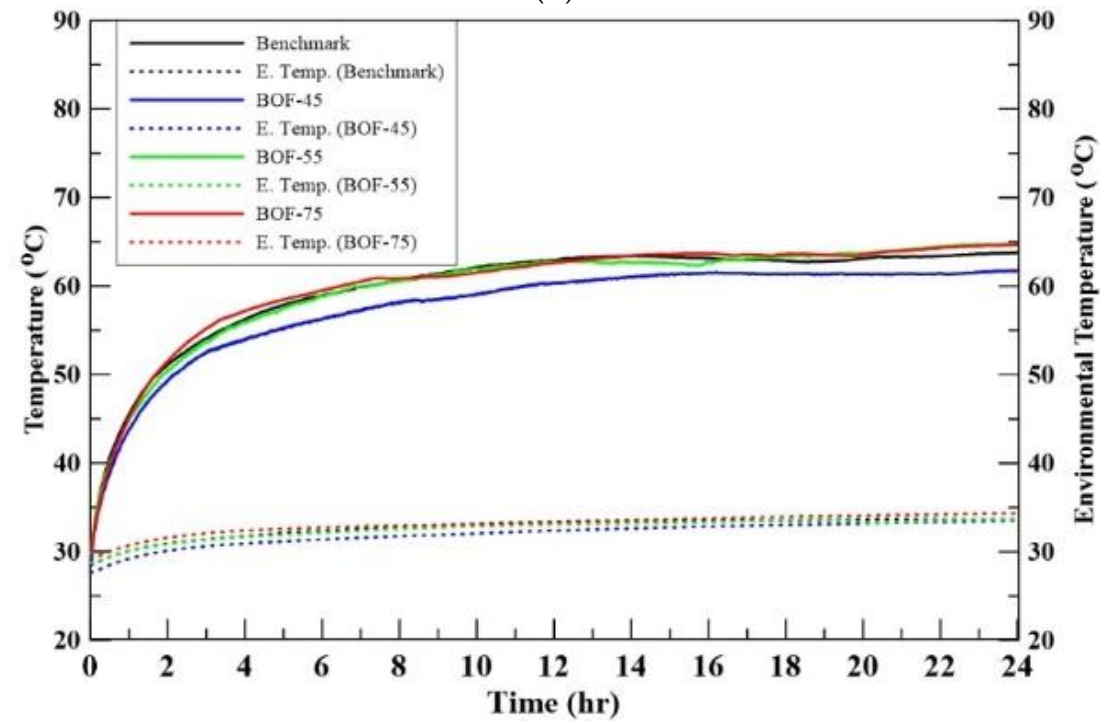

(c)

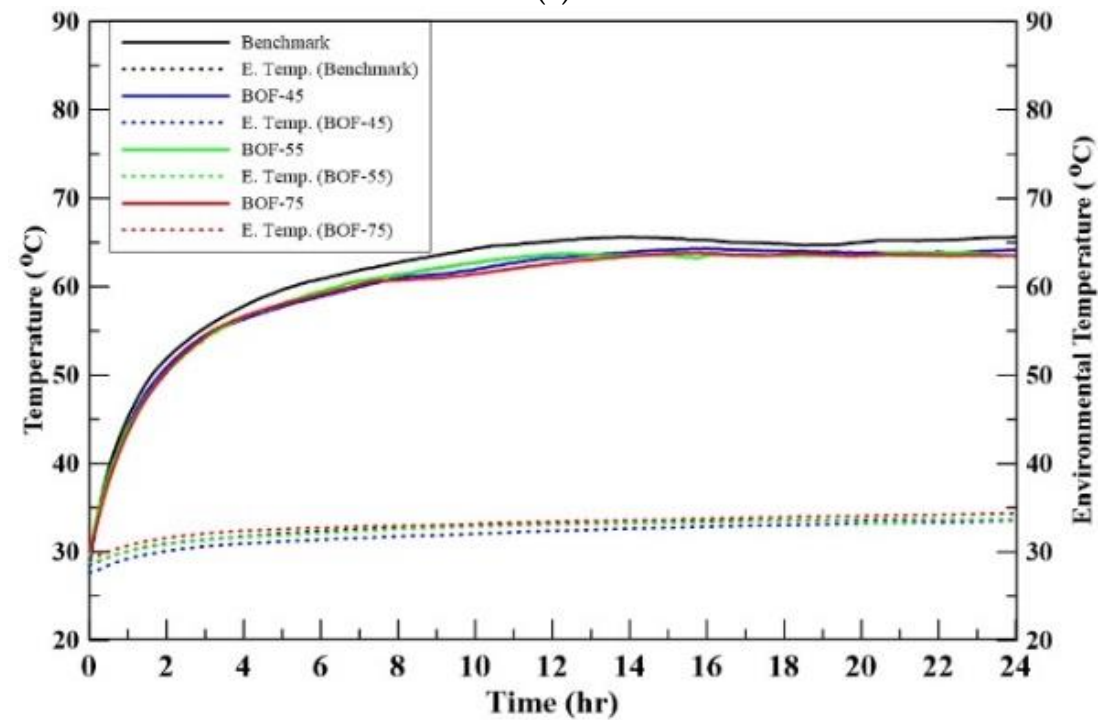

(d)

Figure 10. Cont. 


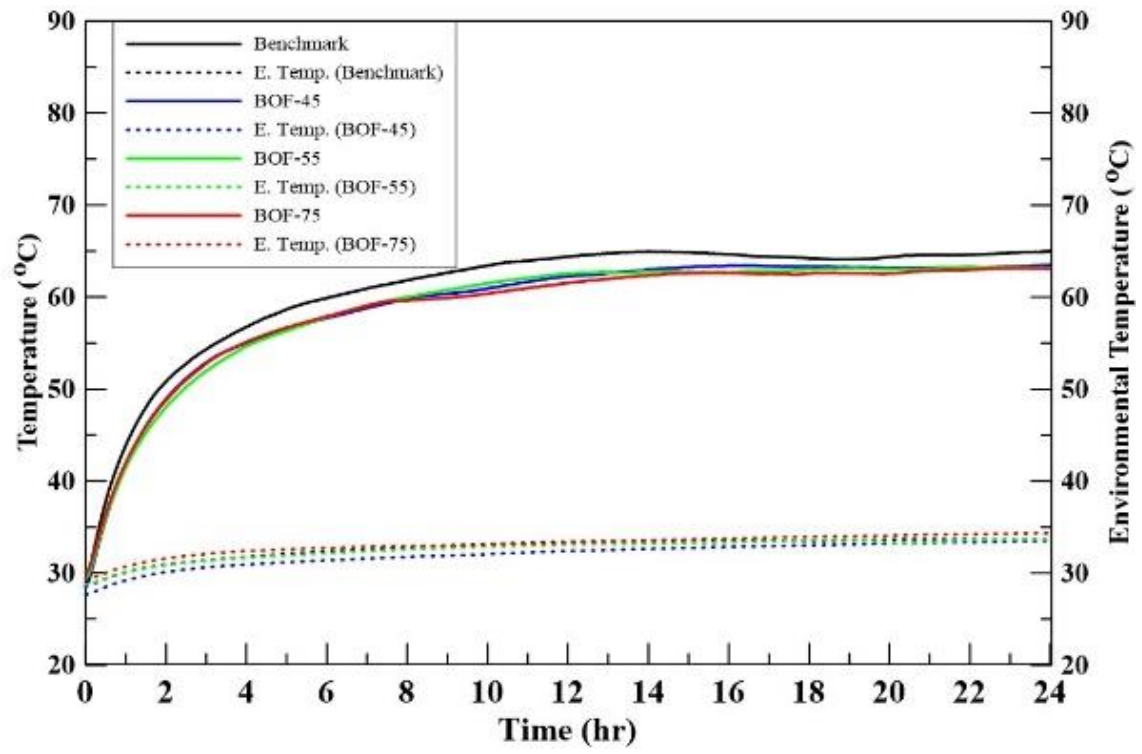

(e)

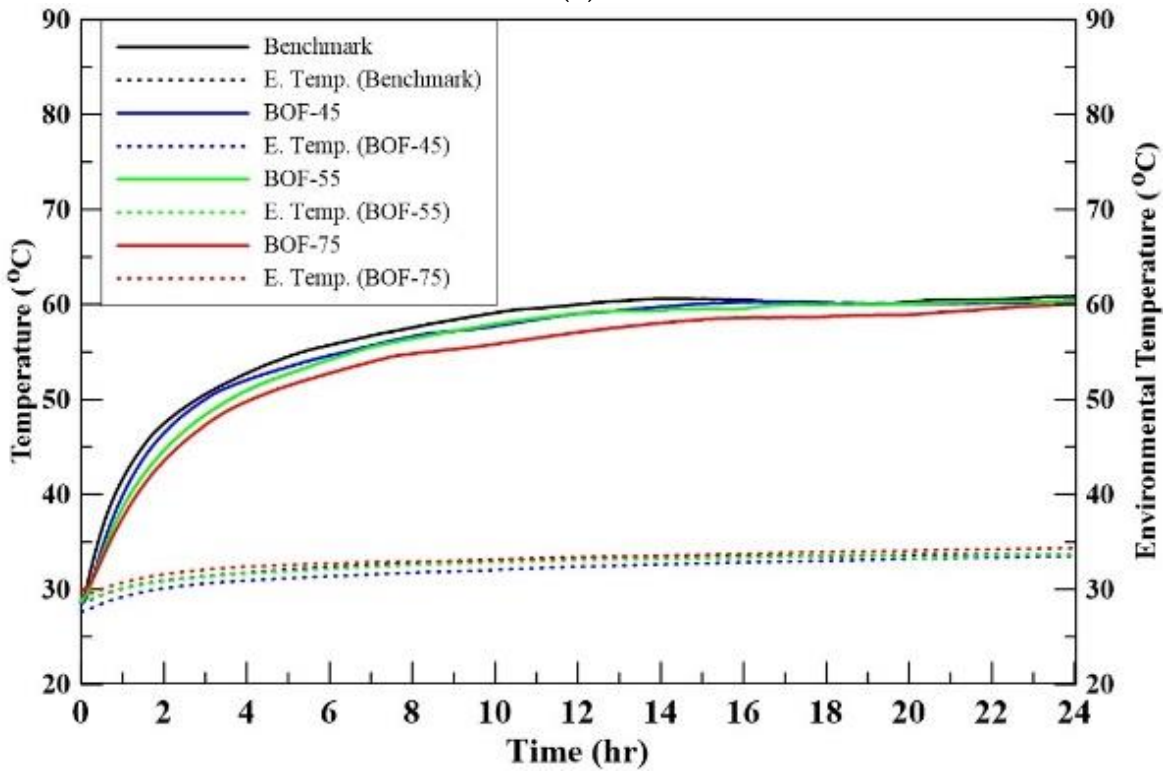

(f)

Figure 10. Temperature-time relationships in the heating period under the radiation intensity of $436 \mathrm{~W} / \mathrm{m}^{2}$ at (a) the top surface; (b) $1 \mathrm{~cm}$ depth; (c) $2 \mathrm{~cm}$ depth; (d) $3 \mathrm{~cm}$ depth; (e) $4 \mathrm{~cm}$ depth; and (f) $5 \mathrm{~cm}$ depth.

The depth-temperature profile taken from the balanced condition at the end of 24 heating hours is shown in Table 5 and Figure 11. In the profile, the temperatures of all specimens declined constantly from $3 \mathrm{~cm}$ to $5 \mathrm{~cm}$ depths. Furthermore, it clearly shows that BOF-75 possessed the lowest temperature of $63.07^{\circ} \mathrm{C}$ at the depth of $4 \mathrm{~cm}$ and $60.04^{\circ} \mathrm{C}$ at the depth of $5 \mathrm{~cm}$. Furthermore, the depth-temperature curves of BOF-55 and BOF-75 were similar. In the profile, their temperatures at the depth of $3 \mathrm{~cm}$ were higher than at the depth of $5 \mathrm{~cm}$, and the temperatures on the surface were higher than that at the depth of $3 \mathrm{~cm}$. On the other hand, the depth-temperature curves of the benchmark and BOF-45 were similar in a different way. These two specimens had the highest temperatures at the depth of $3 \mathrm{~cm}$ and the lowest temperatures on the surface. All the trends above were similar to the results under the radiation intensity of $623 \mathrm{~W} / \mathrm{m}^{2}$. 
Table 5. Temperature $\left({ }^{\circ} \mathrm{C}\right)$ corresponding to different depths at the end of 24 heating hours under the radiation intensity of $436 \mathrm{~W} / \mathrm{m}^{2}$.

\begin{tabular}{|c|c|c|c|c|c|}
\hline Depth & Specimen & Benchmark & BOF-45 & BOF-55 & BOF-75 \\
\hline & $0 \mathrm{~cm}$ & 57.69 & 56.95 & 64.74 & 66.82 \\
\hline & $1 \mathrm{~cm}$ & 61.63 & 61.43 & 60.96 & 62.83 \\
\hline & $2 \mathrm{~cm}$ & 63.78 & 61.76 & 64.60 & 64.69 \\
\hline & $3 \mathrm{~cm}$ & 65.65 & 64.17 & 63.53 & 63.46 \\
\hline & $4 \mathrm{~cm}$ & 64.97 & 63.49 & 61.15 & 63.07 \\
\hline & $5 \mathrm{~cm}$ & 60.88 & 60.40 & 60.28 & 60.04 \\
\hline
\end{tabular}

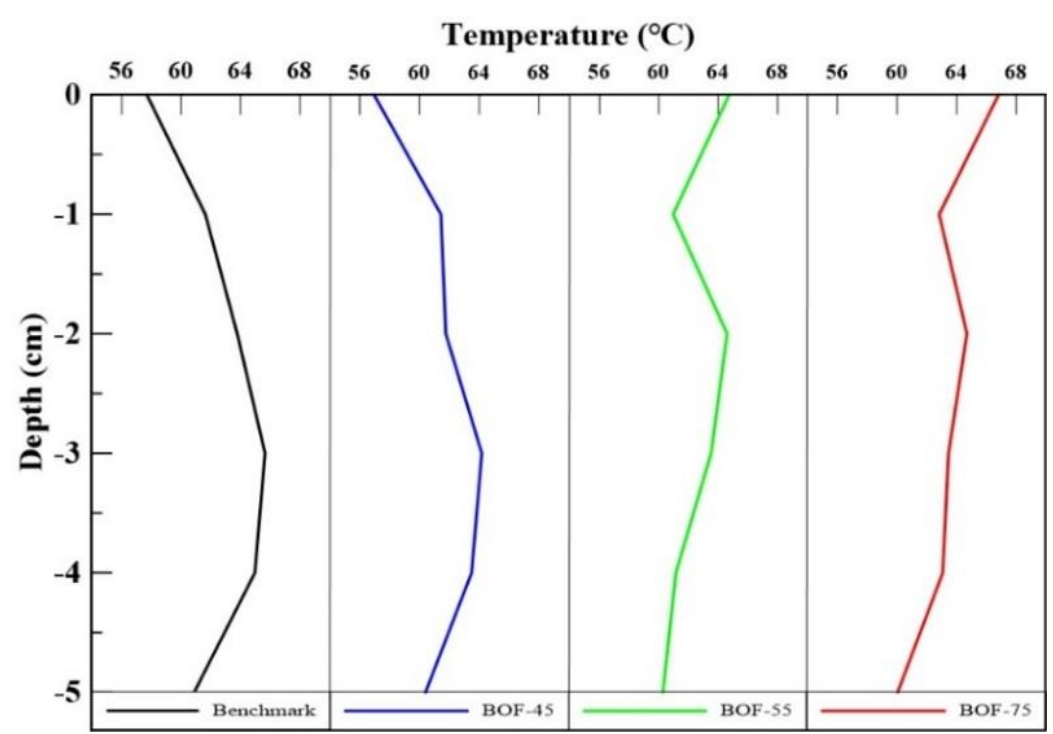

Figure 11. Depth-temperature profile of specimens at the end of 24 heating hours under the radiation intensity of $436 \mathrm{~W} / \mathrm{m}^{2}$.

\subsubsection{Cooling Period}

After 24-h heating, the temperature change in the subsequent 1-h cooling was recorded, as shown in Figure 12. When the heat source was removed, the heat obviously dissipated from the specimens, especially those which possessed higher conductivity. BOF-75 had the lowest thermal conductivity, leading to the slowest cooling rate. In contrast, the benchmark specimen had the highest thermal conductivity, leading to the fastest cooling rate. Also, the cooling rates for each depth gradually became similar, and the rates at the depth of $3 \mathrm{~cm}$ were the most concentrated.

The depth-temperature profiles of specimens within five cooling hours can be seen in Figure 13. The temperature difference between $3 \mathrm{~cm}$ and $5 \mathrm{~cm}$ depths deserves discussion. At the end of five hours, BOF-75 had the lowest temperature on the surface, and its temperature at the depth of $3 \mathrm{~cm}$ was lower than that at $5 \mathrm{~cm}$. With regard to BOF-55, its temperature at the depth of $3 \mathrm{~cm}$ was lower than that at $5 \mathrm{~cm}$ only in the first hour, with a slight difference, and its temperature on the surface was lower than that at the depth of $3 \mathrm{~cm}$ all the time. Also, the temperature of the benchmark at the depth of $3 \mathrm{~cm}$ was higher than that at $5 \mathrm{~cm}$ until the fourth hour.

To sum up, compared to the benchmark asphalt concrete, no matter which radiation intensity was taken, the specimens with partial BOFS replacement showed faster cooling rates when the light was turned off, which might refer to more heat accumulating inside the body. 


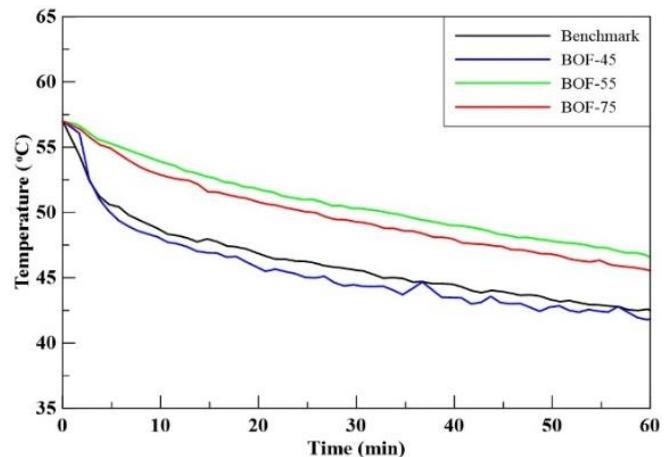

(a)

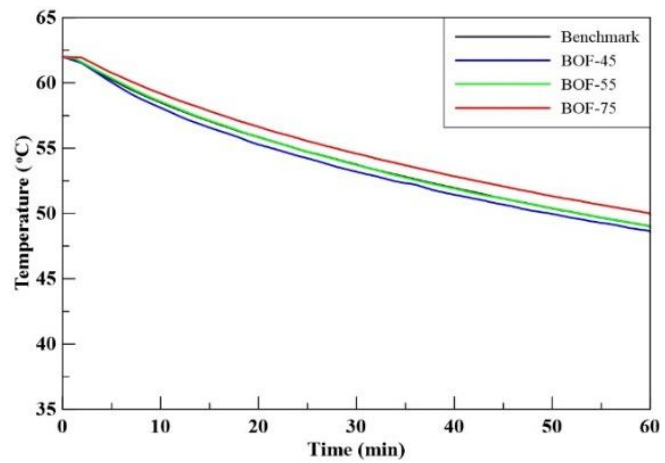

(c)

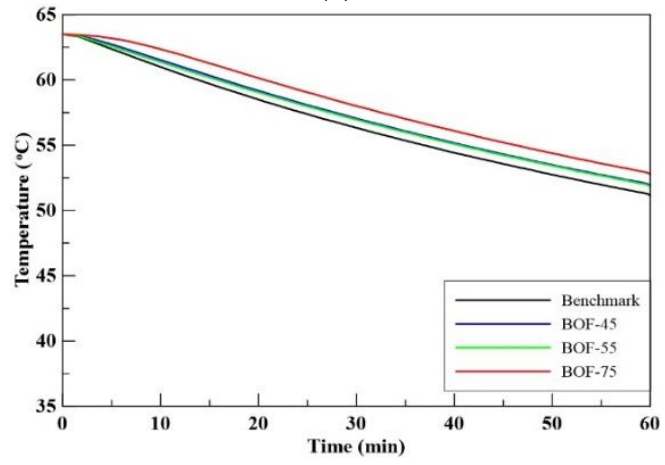

(e)

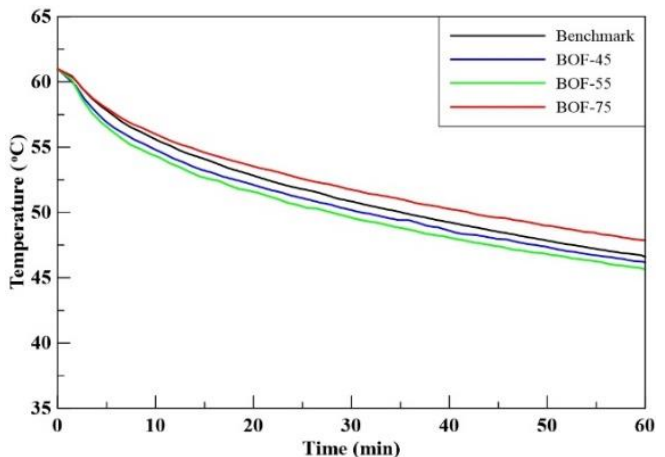

(b)

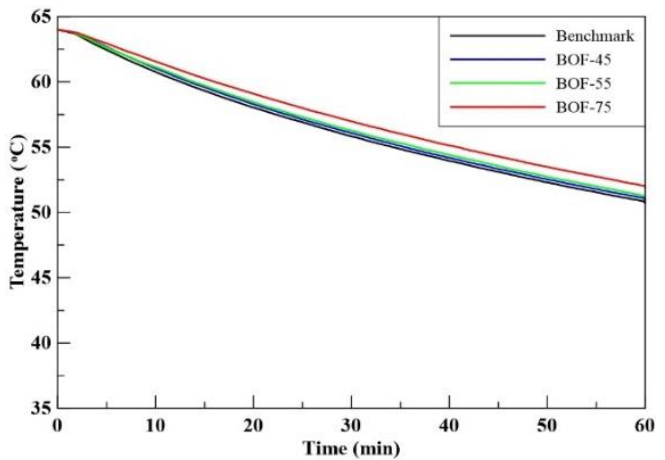

(d)

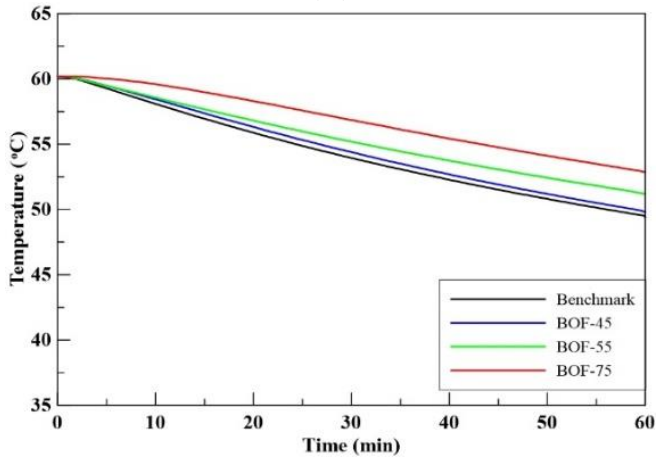

(f)

Figure 12. Temperature-time relationships in the cooling period at (a) the top surface; (b) $1 \mathrm{~cm}$ depth; (c) $2 \mathrm{~cm}$ depth; (d) $3 \mathrm{~cm}$ depth; (e) $4 \mathrm{~cm}$ depth; and (f) $5 \mathrm{~cm}$ depth.

Temperature $\left({ }^{\circ} \mathrm{C}\right)$

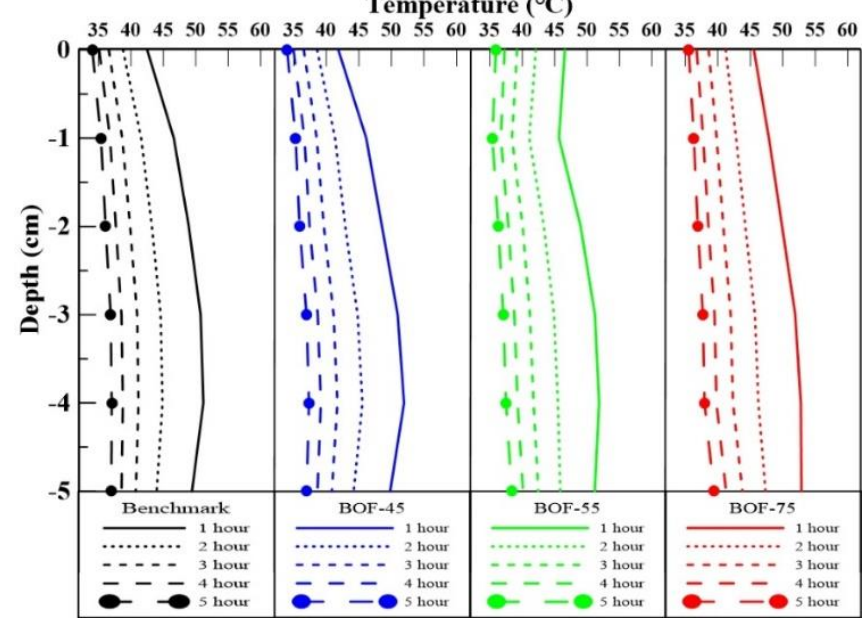

Figure 13. Depth-temperature profile of specimens within five cooling hours in the cooling period. 


\subsection{Outdoor Temperature Measurement}

The temperature-time relationships of specimens in the outdoor test, across both daytime and nighttime for a full $24 \mathrm{~h}$, were measured and are shown in Figure 14 . The specimens' temperature and environmental information were recorded and are shown in Table 6 . The field test results were easily affected by the environmental factors, especially after sunset. Therefore, it is more reliable to use the average ambient temperature for comparison. As shown in Table 6, during the daytime, the benchmark had a higher temperature than the ambient temperature of about $35^{\circ} \mathrm{C}$. Also, unlike the indoor test, specimens could not obtain long-term and sufficient heat from the sun. As a consequence, for BOF-75, its low thermal conductivity and large heat capacity resulted in relatively low temperatures. The calculation of the heat capacity is explained in Section 4.4.

As shown in Table 6, using the ambient temperature of about $30^{\circ} \mathrm{C}$ during nighttime as the comparison basis, the temperatures of the benchmark specimen were generally higher than those of BOF-55 and BOF-75. In terms of results, the use of BOFS did have a positive effect on pavement cooling.

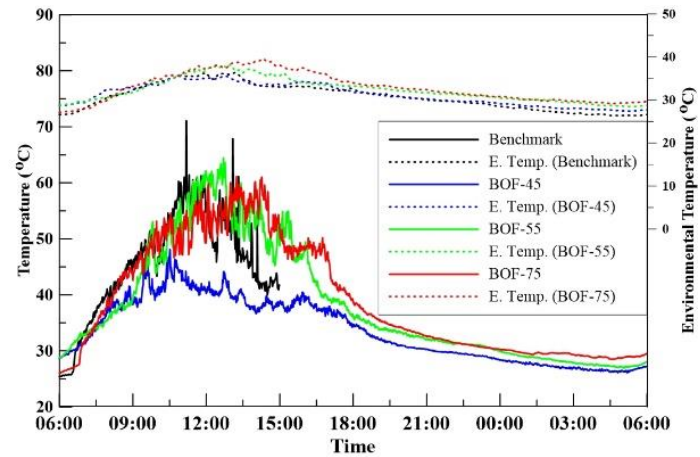

(a)

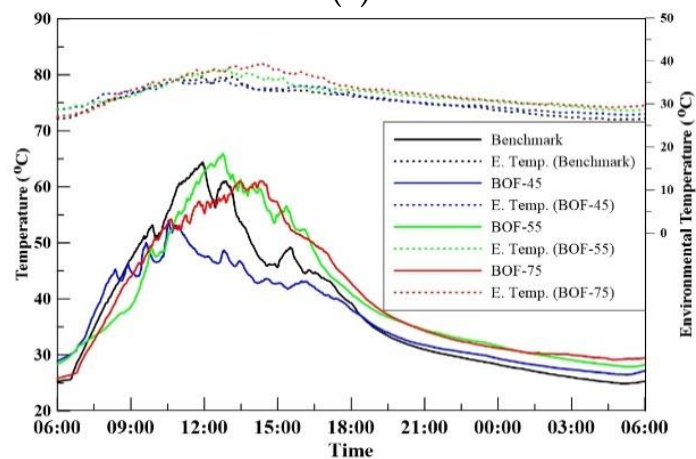

(c)

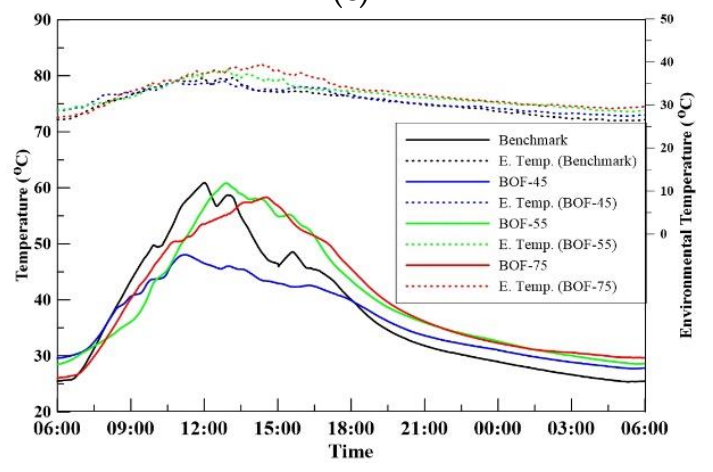

(e)

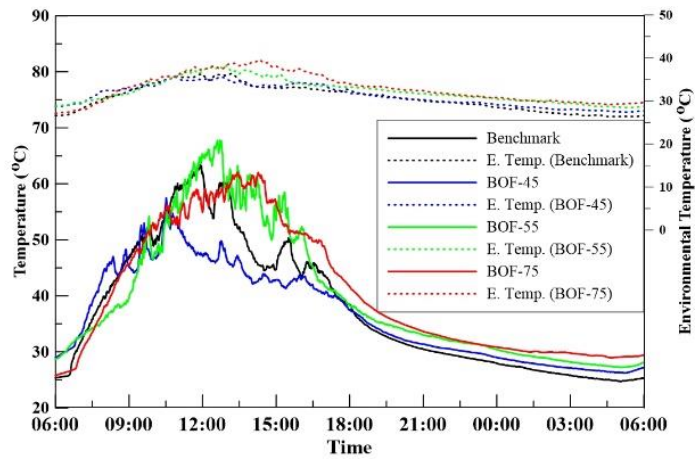

(b)

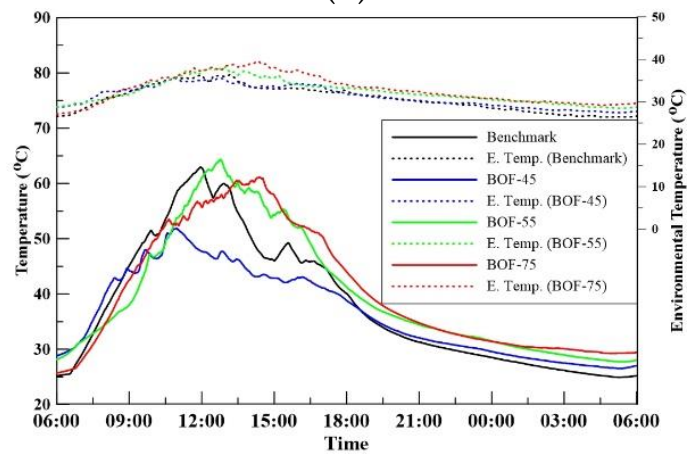

(d)

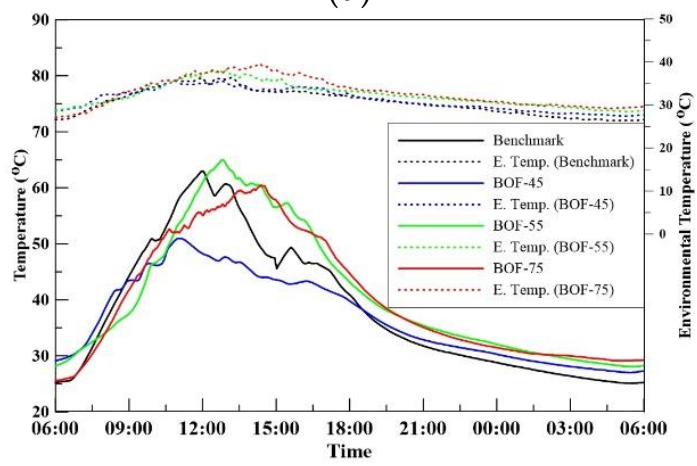

(f)

Figure 14. The temperature-time relationships of specimens in the outdoor test at: (a) the surface; (b) $1 \mathrm{~cm} \mathrm{depth;} \mathrm{(c)} 2 \mathrm{~cm}$ depth; (d) $3 \mathrm{~cm}$ depth; (e) $4 \mathrm{~cm}$ depth; and (f) $5 \mathrm{~cm}$ depth. 
Table 6. Environmental information and temperature corresponding to different depths.

\begin{tabular}{|c|c|c|c|c|c|c|c|c|c|}
\hline \multicolumn{2}{|c|}{ Specimen } & \multicolumn{2}{|c|}{ Benchmark } & \multicolumn{2}{|c|}{ BOF-45 } & \multicolumn{2}{|c|}{ BOF-55 } & \multicolumn{2}{|c|}{ BOF-75 } \\
\hline \multirow{3}{*}{\multicolumn{2}{|c|}{ Time Period }} & 10:00 & 20:00 & $10: 00$ & 20:00 & 9:20 & $22: 40$ & $9: 20$ & $22: 40$ \\
\hline & & $\int$ & $\int$ & $\int$ & $\int$ & $\int$ & $\int$ & $\int$ & $\int$ \\
\hline & & 14:50 & $22: 30$ & $13: 10$ & $23: 30$ & $11: 40$ & 04:10 & $10: 50$ & 06:00 \\
\hline \multicolumn{2}{|c|}{ Average Temperature $\left({ }^{\circ} \mathrm{C}\right)$} & 35 & 30 & 35 & 30 & 35 & 30 & 35 & 30 \\
\hline \multicolumn{2}{|c|}{ Average Humidity (\%) } & 42.23 & 70.81 & 43.90 & 70.13 & 38.40 & 77.26 & 44.70 & 74.24 \\
\hline \multicolumn{2}{|c|}{ Average Solar Radiation $\left(\mathrm{W} / \mathrm{m}^{2}\right)$} & 642.73 & 0 & 412.75 & 0 & 756.34 & 0 & 646.32 & 0 \\
\hline \multirow{6}{*}{$\begin{array}{c}\text { Average } \\
\text { Temperature }\left({ }^{\circ} \mathrm{C}\right) \\
\text { at Various Depths }\end{array}$} & $0 \mathrm{~cm}$ & 51.04 & 29.59 & 41.88 & 29.84 & 50.97 & 29.01 & 49.63 & 29.55 \\
\hline & $1 \mathrm{~cm}$ & 54.54 & 30.32 & 49.11 & 30.82 & 53.09 & 29.39 & 52.21 & 30.01 \\
\hline & $2 \mathrm{~cm}$ & 55.98 & 30.76 & 48.93 & 31.17 & 51.38 & 30.36 & 50.55 & 30.27 \\
\hline & $3 \mathrm{~cm}$ & 55.67 & 31.11 & 48.53 & 31.47 & 49.87 & 30.27 & 49.64 & 30.40 \\
\hline & $4 \mathrm{~cm}$ & 54.69 & 31.61 & 46.22 & 32.96 & 45.99 & 31.36 & 46.73 & 31.05 \\
\hline & $5 \mathrm{~cm}$ & 56.25 & 31.58 & 48.45 & 32.26 & 49.32 & 30.80 & 48.87 & 30.35 \\
\hline
\end{tabular}

\subsection{Heat Capacity, Newton's Cooling and Radiation Cooling}

To confirm the radiation cooling effectiveness of specimens, the loss by radiation cooling was quantified based on several assumptions as follows. The heat which enters the asphalt concrete and then transfers to the ground has only a small impact on pedestrian and human activities; the heat below the specimens was not discussed. On the other hand, the heat on the upper surface of the asphalt concrete specimens is worth further study.

Ideally, when objects receive heat, they transfer it in three ways: reflection, transmission, and absorption. The sum of the energy from these ways must be equal to the energy incident, an illustration of which is shown in Figure 15a. However, it is hard to determine the reflection, transmission, and absorption of specimens realistically, even using a pyranometer. It is impossible to know how much heat has dissipated through radiation. We can only assume that, following the law of conversation of energy, the relationship between the energy entering and leaving the specimen is constant. In this study, the focus was on the cooling period, as shown in Figure 15b. As the temperature of the test body cooled over time under the radiation intensity of $623 \mathrm{~W} / \mathrm{m}^{2}$, the time interval between data was set to $5 \mathrm{~min}$.

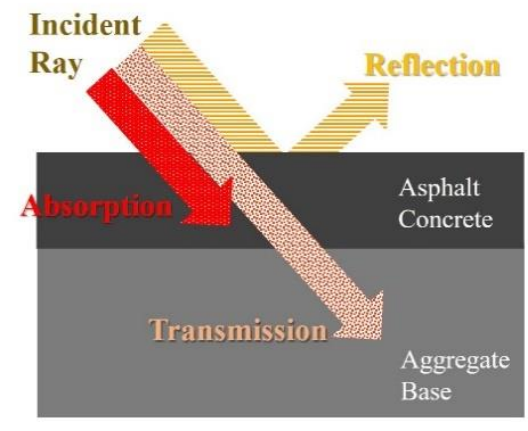

(a)

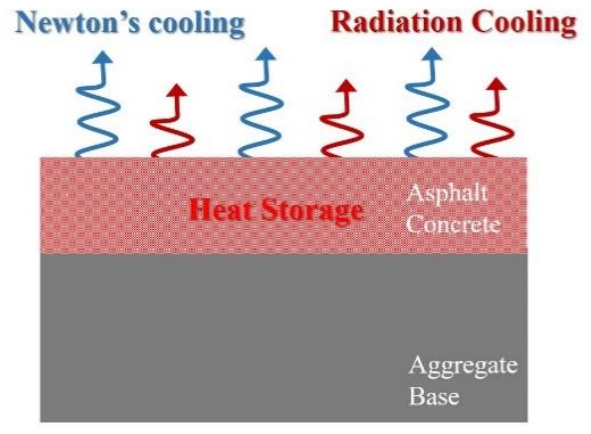

(b)

Figure 15. Relationship between the pavement and (a) basic heat transfer and (b) radiation cooling.

The heat stored in a specimen at various time intervals can be calculated as in Equation (2). In this function, $Q$ is the heat energy in storage $(\mathrm{J}), m$ is the mass of the specimen $(\mathrm{kg}), c$ is the heat capacity of the specimen $(\mathrm{J} / \mathrm{kg}-\mathrm{K})$, and $\Delta T$ is the change in temperature $(\mathrm{K})$.

$$
Q=m c \Delta T
$$

The specimen was divided into five equal parts each with a thickness of $5 \mathrm{~cm}$; the sectional drawing of the specimen is shown in Figure 16. In each part, the temperature at 
the center was the average of the adjoining temperature at the upper and lower part. Then, the sum of the heat stored in each part at the $t$ minute in the cooling period represented the heat storage in the entire specimen at that time. Finally, the heat storage of $(t+5)$ minutes was subtracted from that at the $t$ minute, and added up over $24 \mathrm{~h}$ to obtain the final heat storage of the specimen. This formula is shown in Equation (3), and the calculation results for each hour are presented in Table 7.

$$
\text { The final heat storage in } 24 \mathrm{~h}=\sum_{t=0}^{288}\left(Q_{5 t}\right)-\left(Q_{5(t+1)}\right)
$$

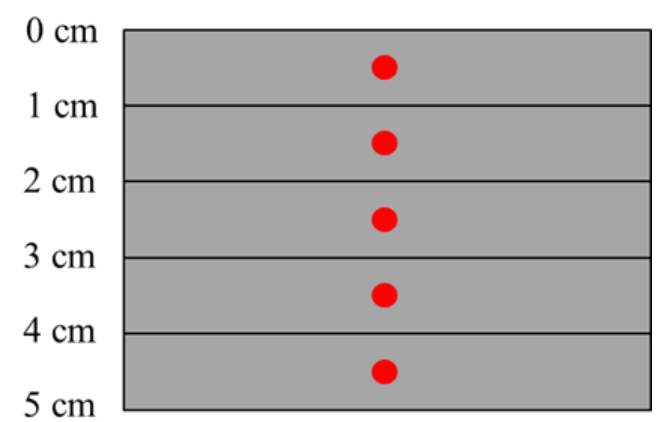

Figure 16. Sectional drawing of the specimen.

Table 7. Heat energy in storage at a different hour (unit: J).

\begin{tabular}{|c|c|c|c|c|}
\hline Hour $\quad$ Specimen & Benchmark & BOF-45 & BOF-55 & BOF-75 \\
\hline 1 & 3871.92 & 3928.44 & 3956.71 & 4691.52 \\
\hline 2 & 2232.71 & 1695.73 & 2430.55 & 2656.65 \\
\hline 3 & 1441.37 & 1526.16 & 1413.11 & 1610.94 \\
\hline 4 & 904.39 & 960.91 & 1017.44 & 1187.01 \\
\hline 5 & 678.29 & 763.08 & 932.65 & 932.65 \\
\hline 6 & 536.98 & 423.93 & 650.03 & 734.82 \\
\hline 7 & 423.93 & 367.41 & 452.20 & 508.72 \\
\hline$\cdots$ & $\cdots$ & $\cdots$ & $\cdots$ & $\cdots$ \\
\hline Sum (24 h) & $255,998.94$ & $233,841.38$ & $288,641.77$ & $306,616.52$ \\
\hline
\end{tabular}

Based on Newton's law of cooling, the heat stored in the pavement is also transferred into the atmosphere, which is called "Newton's cooling" in this study, as shown in Equation (4):

$$
q=h A \Delta T
$$

In this function, $q$ is the power of Newton's cooling transferred out of the specimen (watts), $h$ is the heat transfer coefficient $\left(\mathrm{W} / \mathrm{m}^{2}-\mathrm{K}\right), A$ is the heat transfer surface area $\left(\mathrm{m}^{2}\right)$, and $\Delta T$ is the temperature difference between the environment and specimen $(\mathrm{K})$. The final value for the difference, resulting from Newton's cooling, between specimen and air can be calculated as in Equation (5). Notably, it was necessary to multiply the difference between the total heat of $t$ and that at $(t+5)$ minutes by a time interval of $5 \mathrm{~min}$. The calculation results for each hour are presented in Table 8.

$$
\text { The final Newton's cooling in } 24 \mathrm{~h}=\sum_{t=0}^{288}\left[\left(q_{5 t}\right)-\left(q_{5(t+1)}\right) \times 5\right]
$$


Table 8. Heat energy for Newton's cooling at different hours (unit: J).

\begin{tabular}{|c|c|c|c|c|}
\hline Hour $\quad$ Specimen & Benchmark & BOF-45 & BOF-55 & BOF-75 \\
\hline 1 & 184.69 & 196.26 & 292.53 & 333.16 \\
\hline 2 & 102.92 & 23.08 & 171.10 & 160.02 \\
\hline 3 & 75.39 & 80.00 & 83.71 & 102.77 \\
\hline 4 & 38.81 & 51.77 & 61.17 & 75.05 \\
\hline 5 & 33.77 & 52.61 & 48.01 & 53.64 \\
\hline 6 & 26.46 & 15.76 & 29.53 & 41.18 \\
\hline 7 & 16.92 & 21.13 & 22.06 & 33.01 \\
\hline$\cdots$ & $\ldots$ & $\ldots$ & $\ldots$ & $\ldots$ \\
\hline Sum $(24$ h) & $14,186.33$ & $13,545.51$ & $22,342.61$ & $23,985.92$ \\
\hline
\end{tabular}

Finally, following the above data in Tables 7 and 8 , Newton's cooling energy subtracted from the stored heat energy equals the radiation cooling energy, as shown in Table 9.

Table 9. The heat energy in radiation cooling at different hours (unit: J).

\begin{tabular}{|c|c|c|c|c|}
\hline Hour $\quad$ Specimen & Benchmark & BOF-45 & BOF-55 & BOF-75 \\
\hline 1 & 3687.23 & 3732.19 & 3664.18 & 4358.36 \\
\hline 2 & 2129.79 & 1672.65 & 2259.45 & 2496.63 \\
\hline 3 & 1365.98 & 1446.16 & 1329.40 & 1508.18 \\
\hline 4 & 865.58 & 909.14 & 956.27 & 1111.96 \\
\hline 5 & 644.52 & 710.47 & 884.64 & 879.01 \\
\hline 6 & 510.52 & 408.17 & 620.50 & 693.64 \\
\hline 7 & 407.01 & 346.28 & 430.14 & 475.71 \\
\hline$\cdots$ & $\ldots$ & $\ldots$ & $\ldots$ & $\ldots$ \\
\hline Sum (24 h) & $241,812.61$ & $220,295.87$ & $266,299.16$ & $282,630.60$ \\
\hline
\end{tabular}

The overall amounts of the accumulated heat storage energy, Newton's cooling energy, and the radiation cooling energy are presented in Tables 10-12, respectively. As shown in Table 10, heat storage energy within $7 \mathrm{~h}$ accounted for up to $80 \%$ of heat storage energy within $24 \mathrm{~h}$. We can deduce that the main cooling was completed within $7 \mathrm{~h}$ in the cooling period. Also, BOF-75 had the highest heat storage energy among all the specimens, as shown in Table 10. In the seventh cumulated hour, Newton's cooling energy accounted for about $90 \%$ of the stored energy, as shown in Table 11 . Therefore, the main way of dissipating heat after $7 \mathrm{~h}$ was radiation cooling.

Table 10. Accumulated heat storage energy in the cooling period (unit: J).

\begin{tabular}{|c|c|c|c|c|}
\hline $\begin{array}{ll} & \text { Specimen } \\
\text { Cumulated Hour }\end{array}$ & Benchmark & BOF-45 & BOF-55 & BOF-75 \\
\hline 1 & $138,428.22$ & $116,892.42$ & $160,698.82$ & $156,685.59$ \\
\hline 2 & $172,201.54$ & $149,337.42$ & $196,591.81$ & $198,061.44$ \\
\hline 3 & $191,730.71$ & $167,905.68$ & $217,675.40$ & $222,536.50$ \\
\hline 4 & $204,759.58$ & $180,623.67$ & $231,636.93$ & $238,787.26$ \\
\hline 5 & $214,029.58$ & $190,091.50$ & $241,500.43$ & $251,024.79$ \\
\hline 6 & $220,869.03$ & $197,100.53$ & $249,018.18$ & $260,038.69$ \\
\hline 7 & $226,323.64$ & $203,063.85$ & $254,811.92$ & $267,190.77$ \\
\hline$\cdots$ & $\ldots$ & $\ldots$ & $\ldots$ & $\ldots$ \\
\hline 24 & $255,998.94$ & $233,841.38$ & $288,641.77$ & $306,616.52$ \\
\hline
\end{tabular}


Table 11. Accumulated Newton's cooling energy in the cooling period (unit: J).

\begin{tabular}{|c|c|c|c|c|}
\hline $\begin{array}{ll}\text { Cumulated Hour } & \text { Specimen } \\
\end{array}$ & Benchmark & BOF-45 & BOF-55 & BOF-75 \\
\hline 1 & 9842.91 & 8253.74 & $15,271.91$ & $15,796.84$ \\
\hline 2 & $11,389.49$ & 9985.62 & $17,720.81$ & $18,507.62$ \\
\hline 3 & $12,221.99$ & $10,897.82$ & $19,061.52$ & $20,011.26$ \\
\hline 4 & $12,710.38$ & $11,506.13$ & $19,878.20$ & $20,938.10$ \\
\hline 5 & $13,053.25$ & $11,596.67$ & $20,421.84$ & $21,607.52$ \\
\hline 6 & $13,275.10$ & $12,249.19$ & $20,813.72$ & $22,065.73$ \\
\hline 7 & $13,447.55$ & $12,511.17$ & $21,105.98$ & $22,418.62$ \\
\hline$\cdots$ & $\cdots$ & $\ldots$ & $\ldots$ & $\cdots$ \\
\hline 24 & $14,186.33$ & $13,545.51$ & $22,342.61$ & $23,985.92$ \\
\hline
\end{tabular}

Table 12. Accumulated radiation cooling energy in the cooling period (unit: J).

\begin{tabular}{|c|c|c|c|c|}
\hline $\begin{array}{ll}\text { Cumulated Hour } & \text { Specimen } \\
\end{array}$ & Benchmark & BOF-45 & BOF-55 & BOF-75 \\
\hline 1 & $128,585.31$ & $108,638.68$ & $145,426.92$ & $140,888.75$ \\
\hline 2 & $160,812.05$ & $139,351.81$ & $178,871.00$ & $179,553.83$ \\
\hline 3 & $179,508.72$ & $157,007.86$ & $198,613.89$ & $202,525.24$ \\
\hline 4 & $192,049.20$ & $169,117.54$ & $211,758.73$ & $217,849.17$ \\
\hline 5 & $200,976.34$ & $178,134.83$ & $221,078.60$ & $229,417.27$ \\
\hline 6 & $207,593.93$ & $184,851.34$ & $228,204.45$ & $238,002.96$ \\
\hline 7 & $212,876.09$ & $190,552.68$ & $233,705.94$ & $244,772.15$ \\
\hline$\ldots$ & $\ldots$ & $\ldots$ & $\ldots$ & $\ldots$ \\
\hline 24 & $241,812.61$ & $220,295.87$ & $266,299.16$ & $282,630.60$ \\
\hline
\end{tabular}

In the above calculations, it seems that, under the same radiation intensity, the specimens with higher heat capacities could absorb more heat inside the specimen, and less heat escaped to the environment. And according to Newton's cooling law, the thermal equilibrium occurs under the condition of releasing sufficient energy for the specimen. BOF-75 had a higher surface temperature because it stored as well as absorbed more heat, which is a reasonable result. As far as radiation cooling is concerned, a larger value is considered better, which means that more heat leaves the specimen in this way. BOF-75 had the largest radiation cooling among the specimens.

Based on the results, it can be concluded that BOF-75 had better heat capacity and could dissipate less heat into the environment and absorb more heat than other specimens. Although a higher surface temperature occurred under the same radiation intensity, BOF-75 possessed the best radiation cooling ability in the cooling period among the specimens, and the heat could be transferred into long-wave radiation, which is not easily absorbed by air. In addition, the material emissivity results measured by the Fourier Infrared Spectrometer (FTIR) help to show that BOF-75 demonstrated a better performance in the radiation cooling project.

\subsection{Mechanical Test Results}

The stability values of the specimens were measured according to ASTM D6927 [27]. As shown in Table 13 and Figure 17, the stability values of all specimens were far larger than the standard requirement of $8.006 \mathrm{kN}$, which was set by the Asphalt Institute. As the replacement ratio of BOFS increased, the stability value increased. Among all specimens, BOF-75 had the highest average stability value of $34.54 \mathrm{kN}$. 
Table 13. Stability value of the specimens.

\begin{tabular}{cccc}
\hline Specimen & No. & Stability Value (kN) & Average Stability Value (kN) \\
\hline \multirow{3}{*}{ Benchmark } & 1 & 12.13 & 11.61 \\
& 2 & 12.25 & 17.07 \\
BOF-45 & 3 & 10.43 & 15.91 \\
& 1 & 16.98 & \\
BOF-55 & 3 & 17.68 & 34.54 \\
& 1 & 16.55 & \\
\hline
\end{tabular}

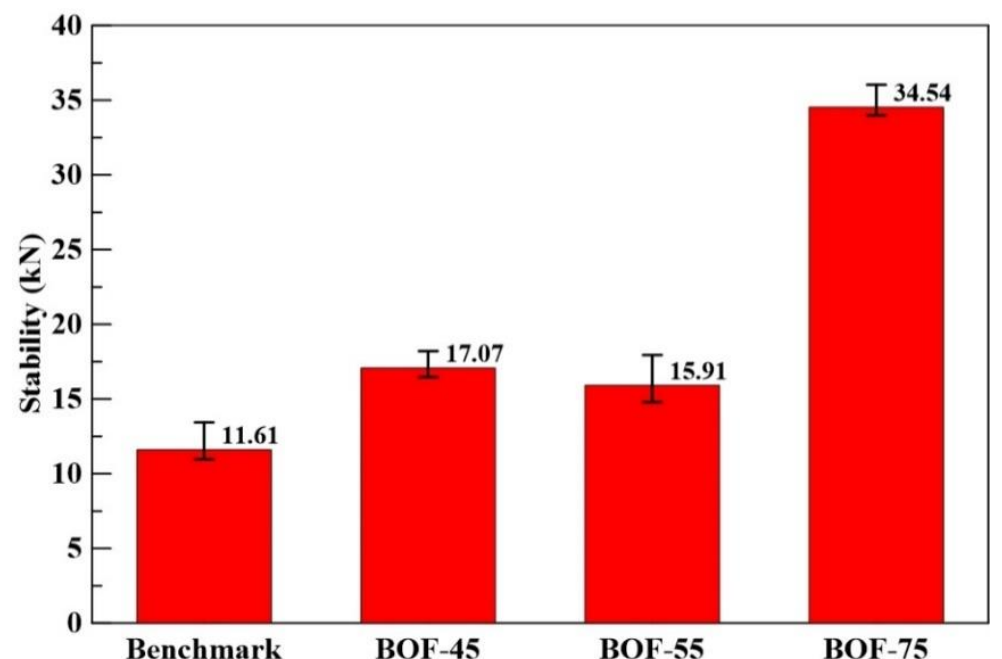

Figure 17. Stability values of the specimens.

Indirect tensile strength, one of the indexes of asphalt concrete, can be inferred from the resistance of rut and crack. Following ASTM D6931 [28], the indirect tensile strength was measured and calculated as shown in Table 14 and Figure 18. It implied that BOFS had a better binding ability with bitumen than natural aggregate did.

Table 14. Indirect tensile strength of the specimens.

\begin{tabular}{cccc}
\hline Specimen & Maximum Load (kN) & $\begin{array}{c}\text { Indirect Tensile } \\
\text { Strength (MPa) }\end{array}$ & $\begin{array}{c}\text { Average Indirect Tensile } \\
\text { Strength (MPa) }\end{array}$ \\
\hline \multirow{3}{*}{ Benchmark } & 5.592 & 0.511 & \\
& 6.524 & 0.612 & 0.568 \\
\hline \multirow{2}{*}{ BOF-45 } & 6.259 & 0.580 & \\
& 11.75 & 1.255 & 1.253 \\
\hline \multirow{2}{*}{ BOF-55 } & 12.09 & 1.251 & \\
& 12.02 & 1.253 & \\
& 13.64 & 1.509 & \\
BOF-75 & 12.26 & 1.364 & 1.253 \\
& 12.30 & 1.368 & \\
\hline
\end{tabular}




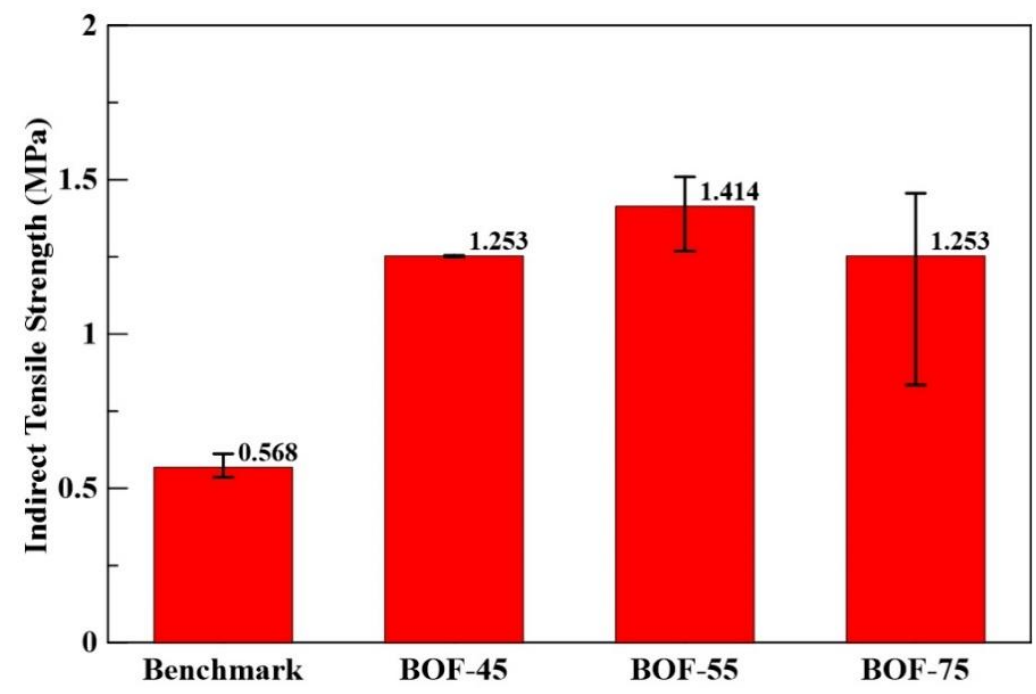

Figure 18. Indirect tensile strength of the specimens.

The BPN was measured according to ASTM E303 [29]. As shown in Table 15, all specimens conformed to the BPN of 45 [30]. Specimens replaced partially by BOFS demonstrated an anti-skid ability, while the flatness was roughly the same. There is no doubt that using asphalt concrete pavement in which natural aggregates have been partially replaced by BOFS affects driving safety.

Table 15. British pendulum number (BPN) of the specimens.

\begin{tabular}{cccccc}
\hline Specimen No. & $\mathbf{1}$ & $\mathbf{2}$ & $\mathbf{3}$ & $\mathbf{4}$ & Average \\
\hline Benchmark & 82 & 83 & 84 & 83 & 83 \\
BOF-45 & 80 & 80 & 81 & 80 & 80 \\
BOF-55 & 79 & 79 & 79 & 80 & 79 \\
BOF-75 & 82 & 80 & 80 & 82 & 81 \\
\hline
\end{tabular}

\section{Conclusions}

Regarding the asphalt concrete with partial BOFS replacement in different proportions, several conclusions can be stated as follows.

1. The BOF-75 specimen had a high emissivity of 0.86 across the sky window $(8-13 \mu \mathrm{m})$ and the thermal conductivity of the specimen decreased as the substitution ratio of BOFS increased.

2. Under two different radiation intensities, the surface temperature order among the specimens was the same. Furthermore, the temperatures from high to low were in the order BOF-75 > BOF-55 > BOF-45 > benchmark specimen.

3. At the end of 24 heating hours, the temperature order at the depth of $3 \mathrm{~cm}$ was opposite to that for the surface, and the temperatures at the depth of $3 \mathrm{~cm}$, from high to low, were in the order benchmark asphalt concrete $>$ BOF-45 > BOF-55 > BOF-75. When the depth was more than or equal to $3 \mathrm{~cm}$, the temperatures remained in the same order.

4. According to the quantitative calculation of the heat storage, under the same radiation intensity, the BOF-75 specimen absorbed the most heat inside the body, contributing to less heat remaining in the environment. In the cooling period, Newton's cooling energy accounted for about $90 \%$ of the stored energy within $7 \mathrm{~h}$, so the main ways of heat dissipation after the seventh hour were radiation and conduction cooling, corresponding to the emission across the urban boundary layer. Therefore, the BOF-75 specimen was considered more favorable to urban heat island mitigation. 
5. The anti-skid index, the BPN value, was far larger than the standard of 45; the stability value complied with the standard of $8.006 \mathrm{kN}$, and BOF-75 could reach $34.54 \mathrm{kN}$. Consequently, BOFS can be successfully applied in pavements.

6. All asphalt concrete with partial BOFS replacement had a greater indirect tensile strength than the traditional concrete. It is very likely that BOFS has a better binding ability with bitumen than natural aggregate does.

7. From the test results, it can be seen that BOFS has great applicability in pavements due to its thermal performance and mechanical properties.

Author Contributions: Conceptualization, Y.-F.L. and C.-H.H.; Data curation P.-A.Y.; Formal analysis, P.-A.Y. Investigation, P.-A.Y. and C.-H.W.; Methodology, Y.-F.L. and C.-H.H.; Project administration, Y.-F.L.; Supervision, Y.-F.L. and T.-W.C.; Writing-original draft, P.-A.Y. and C.-H.W.; Writingreview \& editing, Y.-F.L. and T.-W.C. All authors have read and agreed to the published version of the manuscript.

Funding: This research was funded by the Ministry of Education of Taiwan, under contract No. L7081101-4, and the "Research Center of Energy Conservation for New Generation of Residential, Commercial, and Industrial Sectors" from the Ministry of Education of Taiwan, under contract No. L7091101-19.

Institutional Review Board Statement: Not applicable.

Informed Consent Statement: Not applicable.

Data Availability Statement: Not applicable.

Conflicts of Interest: The authors declare no conflict of interest.

\section{References}

1. NOAA Climate, Climate Change: Global Temperature. Available online: https://www.climate.gov/news-features/ understanding-climate/climate-change-global-temperature (accessed on 22 July 2020).

2. Cao, X.; Tang, B.; Zhu, H.; Zhang, A.; Chen, S. Cooling principle analyses and performance evaluation of heat-reflective coating for asphalt pavement. J. Mater. Civ. Eng. 2011, 23, 1067-1075. [CrossRef]

3. Chen, Q.; Wang, C.; Fu, H.; Zhang, L. Durability evaluation of road cooling coating. Constr. Build. Mater. 2018, 190, 13-23. [CrossRef]

4. Synnefa, A.; Karlessi, T.; Gaitani, N.; Santamouris, M.; Assimakopoulos, D.N.; Papakatsikas, C. Experimental testing of cool colored thin layer asphalt and estimation of its potential to improve the urban microclimate. Build Environ. 2011, 46, 38-44. [CrossRef]

5. Anting, N.; Din, M.F.M.; Iwao, K.; Ponraj, M.; Siang, A.J.L.M.; Yong, L.Y.; Prasetijo, J. Optimizing of near infrared region reflectance of mix-waste tile aggregate as coating material for cool pavement with surface temperature measurement. Energy Build. 2011, 158, 172-180. [CrossRef]

6. Zheng, M.; Han, L.; Wang, F.; Mi, H.; Li, Y.; He, L. Comparison and analysis on heat reflective coating for asphalt pavement based on cooling effect and anti-skid performance. Constr. Build. Mater. 2015, 93, 1197-1205. [CrossRef]

7. Xie, N.; Li, H.; Abdelhady, A.; Harvey, J. Laboratorial investigation on optical and thermal properties of cool pavement nanocoatings for urban heat island mitigation. Build Environ. 2019, 147, 231-240. [CrossRef]

8. Jiang, L.; Wang, L.; Wang, S. A novel solar reflective coating with functional gradient multilayer structure for cooling asphalt pavements. Constr. Build. Mater. 2019, 210, 13-21. [CrossRef]

9. Sha, A.; Liu, Z.; Tang, K.; Li, P. Solar heating reflective coating layer (SHRCL) to cool the asphalt pavement surface. Constr. Build. Mater. 2017, 139, 355-364. [CrossRef]

10. Huang, Z.; Ruan, X. Nanoparticle embedded double-layer coating for daytime radiation cooling. Int. J. Heat Mass Transf. 2017, 104, 890-896. [CrossRef]

11. Feng, C.; Zhang, H.; Li, C.; Jia, W.; Lai, F. The effects of hollow glass microsphere modification on the road performances and thermal performance of asphalt binder and mixture. Constr. Build. Mater. 2019, 220, 64-75. [CrossRef]

12. Du, Y.; Dai, M.; Deng, H.; Deng, D.; Cheng, P.; Ma, C. Incorporating hollow glass microsphere to cool asphalt pavement: Preliminary evaluation of asphalt mastic. Constr. Build. Mater. 2020, 244, 118380.

13. Sun, X.; Qin, X.; Li, S.; Zou, C.; Wang, C.; Wang, X. Characterization of thermal insulating micro-surfacing modified by inorganic insulating material. Constr. Build. Mater. 2018, 175, 296-306. [CrossRef]

14. Du, Y.; Wang, S.; Zhang, J. Cooling asphalt pavement by a highly oriented heat conduction structure. Energy Build. 2015, 102, 187-196.

15. Zhu, Q.; Wang, W.; Wang, S.; Zhou, X.; Liao, G.; Wang, S.; Chen, J. Unilateral heat-transfer asphalt pavement for permafrost protection. Cold Reg. Sci. Technol. 2012, 71, 129-138. [CrossRef] 
16. Wu, C.H.; Huang, C.H.; Li, Y.F.; Lee, W.H.; Cheng, T.W. Utilization of basic oxygen furnace slag in geopolymeric coating for passive radiation cooling application. Sustainability 2020, 12, 3967. [CrossRef]

17. Li, Q.; Ding, H.; Rahman, A.; He, D. Evaluation of Basic Oxygen Furnace (BOF) material into slag-based asphalt concrete to be used in railway substructure. Constr. Build. Mater. 2016, 115, 593-601. [CrossRef]

18. Chen, S.; Lin, D.; Luo, H.; Lin, Z. Application of reclaimed basic oxygen furnace slag asphalt pavement in road base aggregate. Constr. Build. Mater. 2017, 157, 647-653. [CrossRef]

19. Huang, L.S.; Lin, D.F.; Luo, H.L. Effect of field compaction mode on asphalt mixture concrete with basic oxygen furnace slag Constr. Build. Mater. 2012, 34, 16-27. [CrossRef]

20. Xie, J.; Wu, S.; Lin, J.; Cai, J.; Chen, Z.; Wei, W. Recycling of basic oxygen furnace slag in asphalt mixture: Material characterization \& moisture damage investigation. Constr. Build. Mater. 2012, 36, 467-474.

21. Brencis, G.; Smirnovs, J.; Zaumanis, M.; Haritonovs, V. Performance characterization of bituminous mixtures with dolomite sand waste and BOF steel slag. J. Test. Eval. 2012, 40,1-6.

22. Lin, D.; Chou, L.; Wang, Y.; Luo, H. Performance evaluation of asphalt concrete test road partially paved with industrial waste-Basic oxygen furnace slag. Constr. Build. Mater. 2015, 78, 315-323. [CrossRef]

23. Shen, D.H.; Wu, C.M.; Du, J.C. Laboratory investigation of basic oxygen furnace slag for substitution of aggregate in porous asphalt mixture. Constr. Build. Mater. 2009, 23, 453-461. [CrossRef]

24. Amelian, S.; Manian, M.; Abtahi, S.M.; Goli, A. Moisture sensitivity and mechanical performance assessment of warm mix asphalt containing by-product steel slag. J. Clean. Prod. 2018, 176, 329-337. [CrossRef]

25. ASTM D3515. Standard Specification for Hot-Mixed, Hot-Laid Bituminous Paving Mixtures; ASTM: West Conshohocken, PA, USA, 1996.

26. ASTM D6926. Standard Practice for Preparation of Asphalt Mixture Specimens Using Marshall Apparatus; ASTM: West Conshohocken, PA, USA, 2020.

27. ASTM D6927. Standard Test Method for Marshall Stability and Flow of Asphalt Mixtures; ASTM: West Conshohocken, PA, USA, 2015.

28. ASTM D6931. Standard Test Method for Indirect Tensile (IDT) Strength of Asphalt Mixtures; ASTM: West Conshohocken, PA, USA, 2017.

29. ASTM E303-93. Standard Test Method for Measuring Surface Frictional Properties Using the British Pendulum Tester; ASTM: West Conshohocken, PA, USA, 2018.

30. Department of Traffic and Road in Queensland: Traffic and Road Management Manual, TRUM Vol 3, Part 2: Pavement Marking Usage. Available online: https:/ / www.tmr.qld.gov.au/business-industry/Technical-standards-publications/Traffic-and-RoadUse-Management-manual/Volume-3 (accessed on 9 November 2020). 